\title{
1 Genetic determinism of prickles in rose
}

2 NN Zhou ${ }^{1,2}$, KX Tang ${ }^{2}$, J. Jeauffre ${ }^{1}$, T. Thouroude ${ }^{1}$, D. Lopez Arias ${ }^{1}$, F. Foucher ${ }^{1 *} \&$ L.

3 Hibrand-Saint Oyant ${ }^{1 *}$.

41 Université d'Angers, Agrocampus-Ouest, INRAE, GDO-IRHS (Genetics and Diversity of Ornamental Plants,

5 Institut de Recherche en Horticulture et Semences), SFR 4207 QUASAV, 49071 Angers, France

62 National Engineering Research Center for Ornamental Horticulture; Flower Research Institute, Yunnan Academy

7 of Agricultural Sciences, Kunming 650231, China

8 * both authors contributed equally to the work.

$9 \quad$ Corresponding author: zhouning1116@alivun.com

10 Key message: The genetic determinism of prickle in rose is complex,

11 with a major locus on LG3 that controls the absence/presence of

12 prickles on the rose stem.

13 Declarations

14 Author Contributions

15 Contributions

16 NN Zhou designed the projects and obtained funding, planned and performed 17 experiments, collected and analyzed data, and drafted the manuscript. F. Foucher and

18 L. Hibrand-Saint Oyant were responsible for piloting and supervising the project, and 19 for revising the manuscript. KX Tang contributed to designing the project and obtaining

20 funding. J. Jeauffre led the qPCR experiment and analyzed data. T. Thouroude prepared

21 the plant cuttings of $F_{1}$ individuals in the greenhouse. D. Lopez Arias modified the 22 genetic map and helped to develop the R/qtl script.

23 Orcid-ID

24 Zhou NN: orcid.org/0000-0002-5208-6788

25 Tang KX: orcid.org/0000-0003-3807-784X

26 Jeauffre J: orcid.org/0000-0001-6770-0552

27 Thouroude T: orcid.org/0000-0001-7908-7353

28 Lopez Arias D: orcid.org/0000-0001-8129-2786 
Foucher F: orcid.org/0000-0002-3693-7183

Hibrand-Saint Oyant L: orcid.org/0000-0002-4451-8798

\section{Abstract}

Rose is one of the major ornamental plants. The selection of glabrous cultivars is an important breeding target but remains a difficult task due to our limited genetic knowledge. Our objective was to understand the genetic and molecular determinism of prickles. Using a segregating diploid rose $F_{1}$ population, we detected two types of prickles (glandular and non-glandular) in the progeny. We scored the number of nonglandular prickles on the floral and main stems for three years. We performed QTL analysis and detected four prickle loci on $\mathrm{LG1}, 3,4$ and 6 . We determined the credible interval on the reference genome. The QTL on LG3 is a major locus that controls the presence of prickles, and three QTLs (LG3, 4 and 1) may be responsible for prickle density. We further revealed that glabrous hybrids are caused by the combination of the two recessive alleles from both parents. In order to test if rose prickles could originate from a 'trichome-like structure', we used a candidate approach to characterize rose gene homologues known in Arabidopsis, involved in trichome initiation. Four of these homologues were located within the overlapping credible interval of the detected QTLs. Transcript accumulation analysis weakly supports the involvement of trichome homologous genes, in the molecular control of prickle initiation. Our studies provide strong evidence for a complex genetic determinism of stem prickle and could help to establish guidelines for glabrous rose breeding. New insights into the relationship between prickles and trichomes constitute valuable information for reverse genetic 
research on prickles.

\section{Keywords}

53 Trichome, QTL, ZFP5, GIS2, MYB61, MYC1

\section{Introduction}

55 Rose is the major ornamental plant worldwide with a wide diversity, diverse application

56 forms and an extensive cultivated area. Roses are sold as cut flowers, garden plants, in 57 pots, for essential oil, flower tea and culinary purposes. In past centuries, with the continuous efforts of breeders, more than 33,000 varieties of roses were created (Young

59 2007). However, most of these varieties have persistent prickles on the stem. Prickles 60 can protect against herbivores by deterring them from eating the stem (Ronel and Lev61 Yadun 2012; Burns 2014). Furthermore, prickles can be desirable in roses when they are used in hedges to protect properties (as was the case in Reunion Island during the

$6319^{\text {th }}$ century). However, garden roses without prickles are often desirable. Cut roses 64 with prickles are more difficult to handle, harvest and transport and also constitute 65 safety hazards for consumers and workers. Retailers commonly remove prickles from stems prior to sale. Removing the prickles increases labor costs and causes mechanical

67 damage to the stems, which affects vase life and ornamental value. Although a strong market demand to develop roses without prickles exists (Nobbs 1984; Debener 1999; Canli 2003; Canli and Skirvin 2003; Canli and Kazaz 2009), relatively little is known about the genetic and molecular bases of prickle initiation and development.

71 In plants, prickles are described as outgrowths of the epidermis and subjacent layers 
that lack vasculature, and mainly consist of lignin, suberin, cellulose and hemicellulose (Asano et al. 2008; Li et al. 2012). In rose and raspberry, it was thought that prickles were modified glandular trichomes that differentiate at the time of lignification into their final prickle morphologies (Kellogg et al. 2011).

Until recently, only a few studies had been published about the molecular regulation of prickle development, but great progress has been made in trichome initiation and development, especially in Arabidopsis. Several transcription factors (TFs) such as MYB, bHLH, WD40, WRKY and C2H2 zinc finger families' proteins have been identified as being involved in trichome initiation and development (reviewed in Balkunde et al. (2010), Pattanaik et al. (2014), Ma et al. (2016a), Huchelmann et al. (2017) and Chopra et al. (2019)). A trimeric activator complex consisting of MYB (GLABRA1) - bHLH (GLABROUS3/ENHANCER OF GL3) - WDR (TRANSPARENT TESTA GL1) plays a key role in trichome development (Zhang 2003; Kirik et al. 2005; Patra et al. 2013). This trimeric complex finely regulates the temporal and spatial expression of GLABRA2 (GL2) and TRANSPARENT TESTA GL2 (TTG2), determining the fate and pattern of trichome precursor cells (Rerie et al. 1994; Ishida et al. 2008). The bHLH family genes, MYC1 and TT8, belong to the same clade as GL3. AtMYCl acts as a positive regulator of trichome initiation (Symonds et al. 2011; Zhao et al. 2012), and AtTT8 controls trichome development on leaf margins (Maes et al. 2008). AaMYB1 and its orthologue AtMYB61, belonging to the R2R3MYB subfamily, were thought to affect terpene metabolism and trichome development in A. annua and A. thaliana, respectively (Matías-Hernández et al. 2017). 
The active TTG1 trimeric complex can be repressed by R3 MYB subfamily genes: $T R Y / C P C / T C L 1$ act as negative regulars by competing with $G L 1$ for binding to $G L 3$ (Wang et al. 2008; Wester et al. 2009; Wang and Chen 2014). The active TTG1 complex, in interaction with $T T G 2$, regulates the expression of the R3 MYB inhibitors that move to the neighboring cells where they repress trichome initiation (Pesch and Hülskamp 2004; Pesch et al. 2014).

Different growth regulators positively affect trichome initiation, such as GA3, cytokinin and jasmonic acid (Traw and Bergelson 2003), through the activation of GL1 (Gan et al. 2006). Different $\mathrm{C} 2 \mathrm{H} 2$ zinc-finger proteins such as GLABROUS INFLORESCENCE STEM (GIS), GIS2, GIS3, ZINC FINGER PROTEIN5, 6 and 8 (Gan et al. 2006; Gan et al. 2007) include GA and cytokinin signaling pathways (Zhou et al. 2013). The novel transcription factor TRP interacts with ZFP5 and negatively regulates trichome initiation through the gibberellic acid pathway (Kim et al. 2018). In diploid rose, the presence of prickles on the stem was assumed to be controlled by a single dominant gene (Debener 1999; Shupert et al. 2007) located on linkage group 3, LG3 (Linde et al. 2006). Furthermore, two QTLs were detected on LG3 with the scoring of prickle density (Crespel et al. 2002). Using two $F_{1}$ progenies, Hibrand-Saint Oyant et al. (2018) also identified a large QTL (or two neighboring QTLs) on LG3 (between position $31 \mathrm{Mb}-46.5 \mathrm{MB}$ corresponding to the end of the chromosome 3) and a significant association between position 31 and $32.4 \mathrm{Mb}$ using a GWAS approach. In tetraploid roses, three QTLs were identified in relation to the number of prickles on the stem: two located on LG2 and one on LG3 (Koning-Boucoiran et al. 2009). Using the 
same K5 population with the same phenotype data but a new genetic map, different

117 QTLs were detected on LG3, 4 and 6 and on LG2 (one year) (Bourke et al. 2018).

118 Recently, a WRKY transcription factor, homologous to Arabidopsis TTG2, was located

119 close to a QTL controlling prickle density, and the gene transcripts are differentially

120 accumulated between prickle and prickless roses (Hibrand-Saint Oyant et al. 2018).

121 In this study, our objectives were to decipher the genetic determinism of stem prickles

122 in rose and to characterize candidate genes involved in prickle initiation and

123 development. First, we defined the different types of prickles on the stem and studied

124 them separately. Using an $\mathrm{F}_{1}$ progeny, we detected QTLs and their position in the rose

125 genome sequence. We further analyzed how the alleles of the major QTLs affect the

126 presence of prickles. We identified putative candidate genes (homologues of genes

127 involved in trichome initiation and development in Arabidopsis) and studied their

128 transcript accumulation. That study suggested that prickles and trichomes may carry

129 two different genetic pathways, providing new insights into the relationship between 130 prickles and trichomes.

\section{Materials and methods}

\section{$132 \quad$ Plant material}

133 A progeny of 151 diploid $\mathrm{F}_{1}$ hybrids obtained from a cross between the female Rosa

134 chinensis 'Old Blush' $(\mathrm{OB}) \times$ the male $R . x$ wichurana $(\mathrm{RW})$ was used for map 135 construction (described in Hibrand-Saint Oyant et al. 2018) and QTL analysis. The 136 plants were grown in a field and managed by the Horticulture Experimental Unit 137 (INRAE, Angers, France). The plants were pruned each December. In the following 
spring, new stems developed from the axillary buds from the old pruned stems, and are

139 referred to as "floral stems" since they develop flowers. Later, new stems arise from the

140 base of the plant and are referred to as "main stems". They remain vegetative in once-

141 flowering individuals and may become floral in continuous-flowering individuals.

\section{Phenotypic data collection and analyses}

143 To score prickle density, we selected three independent floral and main stems for each

$144 \quad F_{1}$ progeny and the two parents. The prickle numbers were counted for each selected

145 stem on four internodes (located in the middle of the stem) for three years $(2016,2017$

146 and 2018).

147 Statistical analysis and visualization were performed using $\mathrm{R}$ version 3.2.3. We

148 visualized the frequency distribution and Q-Q plot using the 'hist', 'legend', 'qqnorm'

149 and 'qqline' functions. We performed mixed-factorial ANOVA analysis with 'aov'. A

150 'shapiro.test' was used to test the normality of the original data and the ANOVA

151 residuals. When the null hypothesis was negated, 'kruskal.test' was used to test if there

152 was any significant difference between the replicate shoots, years and the type of stem

153 variance. 'pairwise.wilcox.test' with 'p.adjust.method $=B H$ ' was used to calculate

154 pairwise comparisons between group levels with corrections for multiple testing. We

155 displayed the distribution of prickle density with a boxplot to compare the difference

156 between the variance using the ggplot 2 and ggpubr packages. 
Variance components were estimated with the restricted maximum likelihood (REML) method using the 'sommer' package. Phenotype variance components of prickle density were obtained using the following model:

$$
P_{i j l r}=\mu+G_{i}+S_{l}+Y_{(l) j}+G S_{i l}+G Y_{i j}+\varepsilon_{i j l},
$$

where $P_{i j l r}$ is the phenotypic value of a trait counted on a triplicate stem $r$ of the stem type $l$ of the individual $i$ in the year $j, \mu$ is the overall mean, $G_{i}$ is the random effect of genotype $i, S_{l}$ is the random effect of stem type $l, Y_{(l) j}$ is the random effect of year $j$ nested in stem type $l, G S_{i l}$ is the random interaction between genotype $i$ and stem type $l, G Y_{i j}$ is the random interaction between genotype $i$ and year $j$, and $\varepsilon_{i j l}$ is the random residual error.

The phenotypic variance $\left(\sigma_{P}^{2}\right)$ of stem prickles was divided into the variance of genotypic effect $\left(\sigma_{G}^{2}\right)$, genotype $\times$ year interaction $\left(\sigma_{G Y}^{2}\right)$, genotype $\times$ stem type interaction $\left(\sigma_{G S}^{2}\right)$, and the residual error variance $\left(\sigma_{E}^{2}\right)$.

Narrow-sense heritability $\left(\mathrm{h}^{2}\right)$ was calculated as follows:

$h^{2}=\sigma_{G}^{2} /\left(\sigma_{G}^{2}+\sigma_{G Y}^{2} / \mathrm{y}+\sigma_{G S}^{2} / \mathrm{s}+\sigma_{E}^{2} / y s r\right)$

where $y$ is the number of years, $r$ is the number of replication shoots per individual, and $s$ is the number of stem types (PF and PM).

\section{Genotypic data}

The genetic determinism was conducted using the genetic map previously obtained by Hibrand-Saint Oyant et al. (2018) and modified by Lopez-Arias et al. (in prep).

\section{QTL Analysis}

In this study, we performed QTL detection for prickles on the floral (PF) and main (PM) 
stems from data scored in 2016, 2017, 2018 (referred to as PF2016, PF2017, PF2018, PM2016, PM2017 and PM2018, respectively). QTL analyses were carried out using the $\mathrm{R} / \mathrm{qtl}$ in $\mathrm{R}$ version 3.2.3. Based on the non-normal phenotype distribution data, single QTL analysis and LOD scores were calculated using the 'scanone' function with nonparametric model (model="np", ties.random $=$ FALSE, method $=$ "em") and the twopart model $($ model="2part", upper = FALSE) $($ Boyartchuk et al. 2001).

In the non-parametric model, the genome-wide and chromosome-wide significance thresholds of LOD scores were estimated by permutations tests $($ n.perm $=1000$, n.cluster $=20$ ). The Bayesian credible interval was computed with 0.95 and 0.99 coverage probabilities. When QTLs for different traits had overlapping 0.95 credible intervals, they were declared to be a potentially "common QTL (cQTL)" (Kawamura et al. 2011). The percent of variance explained by each QTL was calculated by 'makeqtl' and 'fitqtl' with a 'normal' model.

In the two-part model, the phenotype was separated into two parts: first, the trait value was considered as without (0) or with (1) prickles; if it had prickles, the trait value above zero was assumed to be normally distributed. Three LOD scores for each genomic position were calculated: $\operatorname{LOD}(p)$ and $\operatorname{LOD}(\mu)$ were calculated for binary traits $(0$ or 1$)$ and non-zero phenotype quantitative traits $(>0)$, respectively; $\operatorname{LOD}(p, \mu)$ is simply the sum of the LOD scores from the two separate analyses (Broman 2003). The genome-wide significance thresholds of three LOD hypotheses were also estimated by 1000 permutation tests and summarized by a 0.05 alpha threshold. The percent of variance explained was calculated by 'makeqtl' and 'fitqtl' with 'binary' and 'normal' 
models for $\operatorname{binary}(p)$ and quantitative $(\mu)$ traits.

\section{Selection of rose candidate genes involved in prickle density}

Proteins involved in trichome initiation and development were selected in A. thaliana from the TAIR database (https://www.arabidopsis.org) with searching terms GL1, MYB82, MYB61, CPC, TRY, GL3, TT8, MYC1, TTG1, TTG2, ZFP5, ZFP1, GIS2, GIS3, GL2. Rose homologues were searched using BLASTp in the Rosa chinensis Genome v1.0 (Hibrand-Saint Oyant et al. 2018). In addition, we also searched the transcription factors (TF) belonging to the bHLH, WD40, R2R3MYB, C2H2 and WRKY families in rose and which were located on the major cQTL interval of LG3. Using Geneious 9.1.7, ‘Multiple Align’ was performed for the family gene sequences. Conserved domains were used to build phylogenetic trees using the 'Geneious Tree Builder' tool with the Jukes-Cantor genetic distance model and the UPGMA tree build method. The rose candidate genes were named according to the following nomenclature corresponding to $R c$ (for Rosa chinensis) added to the corresponding gene name in Arabidopsis, e.g., RcTTG2 for the rose TTG2 homologue.

\section{Gene expression analysis}

Primers were designed using Primer Premier 5.0 software. To ensure the specificity of the primers, forward and reverse primers were designed in the last exon and in the beginning (first $100 \mathrm{bp}$ ) of the 3'UTR. Primer length was between 18 and $25 \mathrm{bp}$, product length was between 70 and $200 \mathrm{bp}$, GC content was between $40 \%$ and $60 \%$, and the annealing temperature was $58 \sim 65{ }^{\circ} \mathrm{C}$. Primers are listed in Supplementary Table 1.

For the qPCR experimental design, we selected four contrasting once-flowering 
223 individuals from the OW progeny for prickle density: two with no prickles (OW9067 224 and OW9068) and two with prickles (OW9137 and OW9071 with means of 2.5 and 4 225 prickles per internode on the main stem, respectively). The materials were sampled in 226 April 2018 in a greenhouse (three biological replicates). Stems were harvested at 227 different stages of prickle development for roses with prickles, and stems at the same 228 stages for roses without prickles (Supplementary Figure 1). Total RNA was extracted 229 using the NucleoSpin RNA Plus-XS kit for early stages (I and IIa) and using the 230 NucleoSpin RNA Plus-kit for later stages (IIb, IIc and III) according to the 231 manufacturer's instructions, with minus modifications (2\%PVP40 in lysis buffet). The 232 purity of the RNA was checked on 1\% agarose gel, and the concentration was measured 233 by an UV spectrophotometer. cDNA was obtained from 500 ng of total RNA using 234 iScriptTM Reverse Transcription Supermix for RT-qPCR (Bio-Rad, Hercules) 235 accordant to the manufacturer's instructions. The purity and quality of the cDNA were 236 checked by performing PCR amplification with a blank and RW's DNA sample control, 237 and the concentration was measured with a UV spectrophotometer. RT-qPCR reactions 238 were performed using the soAdvancedTM Universal SYBR ${ }^{\circledR}$ Green Supermix (Bio$239 \mathrm{Rad}$ ) on the CFX Connect Real-time PCR system (Bio-Rad). The gene efficiency was 240 evaluated with a serial dilution of the thirty cDNAs pooling $(1: 10,25,50,100,250$, $241500,1000)$. A 1:25 dilution of each cDNA was used to analyse the expression pattern 242 of ten candidate genes and two reference genes UBC and TCTP (Randoux et al. 2012). 243 Data collection was performed using the Bio-Rad CFX Maestro1.1. Amplification 244 efficiency of the ten genes ranged from $90.5-104.1 \%$. The reference genes $U B C$ and 
TCTP presented high expression stability in all the samples.

For the technical replicates, potential outliers were excluded from the analysis when the

247 standard deviation (SD) of samples is higher than 0.5 . Only seven technical replicates

248 (seven out of 390) were excluded: CPC in PIIb (biological group A, C) and in NPIIc

249 (group A), GIS2 in NPIIc (group C), NPIII (group B) and PIII (group B).

250 Normalized expression ( $\Delta \Delta \mathrm{Cq}$ ) was calculated using Bio-Rad Maestro1.1 software by

251 applying the 'gene study' tool. The cluster analysis for sample and target genes with the

252 mean value of normalized expression was performed using $\mathrm{R}$ software with the

253 'pheatmap' package. NP samples were used as controls to compare the normalized

254 expression of genes between P and NP samples in the different stages. |Fold change

$255(\mathrm{FC}) \mid>2$ and the Wilcoxon signed rank test $(\mathrm{p}$-value $<0.05)$ as cut-off values in scatter

256 plots were used to demonstrate the significant difference of normalized expression

257 between $\mathrm{P}$ and NP samples. NPI was used as a control to visualize the relative 258 normalized expression during stem development in prickle and glabrous stems.

\section{Results}

\section{1-Type, distribution and genetic variability of stem prickles in OW progeny}

261 Both parents of the $\mathrm{F}_{1}$ progeny ('Old Blush' and $R$. $x$ wichurana) present prickles on 262 their stems (Figure 1a) (a mean of around ten prickles on four internodes). In the $F_{1}$ 263 progeny, hybrids without prickle can be observed (14 out of 151; no prickles on the 264 three stems scored over three years). These hybrids with glabrous stems (Figure 1b) 265 are referred to as 'prickless' individuals (Figure 1c). Out of the $137 \mathrm{~F}_{1}$ individuals with 266 prickles (Figure 1b), nine hybrids were nearly prickless (prickle number on four 
internodes $<1$ for three scored years and two types of stems; Figure 1d, Supplementary

Figure 2), and numerous stems were glabrous for some individuals, whereas other stems presented a few prickles (variable between the genotypes with unstable states between years and types of stems). Macroscopic analysis shows that parents that present prickles

271 originated from a 'non-glandular' structure. These prickles are referred to as Non272 Glandular Prickles (NGP). All the $\mathrm{F}_{1}$ prickly individuals (137 out of 151) have NGP. 273 However, some individuals with NGP prickles also present another type of prickle (27 274 out of 137). These prickles present a 'glandular head' structure and are referred to as 275 Glandular Prickles (GP) (Figure 1b and 1c, Supplementary Figure 2). Since the 276 presence of GP in the OW progeny is rare (27 and 12 out of 151 on flowers and main 277 stems, respectively; Figure 1d) and very irregular, we decided to consider only NGPs 278 in this study.

279 For the $151 \mathrm{~F}_{1}$ progenies, the number of NGPs on four internodes of floral (PF) and 280 main (PM) stems ranged from 0 to 52 and from 0 to 48, respectively (Supplementary 281 Figure 2). Among them, OW9106 and OW9107 have a much higher prickle density (28 to 52 in the scored years) than the others. As for the two parents, OB and RW have an average of 11.1 and 8.7 on PF, and an average of 11.8 and 9.2 on PM, respectively

284 (Figure 1a, Table 1). The ranges of NGP numbers in the $\mathrm{F}_{1}$ hybrids were obviously 285 beyond the values of the two parents, indicating a transgressive segregation.

286 The Shapiro-Wilk normality test and the Q-Q plot of original data $(\mathrm{W}=(0.692 \sim 0.936)$, $287 \mathrm{p}<2.96 \times 10-8)($ Supplementary Figure 2$)$ and variance residuals $(\mathrm{W}=0.88591, \mathrm{p}$ 288 value $<2.2 \mathrm{e}-16$ ) showed that the NGP densities on stems in the $\mathrm{F}_{1}$ population were not 
normally distributed. We tried to transform data $(\log 10, \mathrm{SQRT}$, box-cox) to make them normal but without success. The Kruskal-Wallis test reveals a genotype effect, a year

291 effect and a stem effect (Table 1$)$. The high heritability $\left(\mathrm{h}^{2} \approx 0.97\right)$ demonstrated that 292 the genetic analyses of stem prickle of this population were reliable (Table 1).

293

294

\section{2- QTL analysis}

\subsection{Non-parametric QTL analysis}

For the female and male maps, strong QTLs were detected on LG3 for the two types of stems and for the three years (igure 2 and Table 2). The LOD scores are higher for the male map (between 8 and 11.5) and relatively lower for the female map (between 2.3 and 6.2). These QTLs explained between 6.65 to $37.4 \%$ of the phenotypic variance. The locations of these QTLs are very close. Indeed, on the female map, the marker at the peak of the QTLs is the same for both types of stems (Rh12GR_16570_782, 51.1 cM, located on the chr3 at 44,459,262 bp according to the Rosa chinensis Genome v1.0 (Hibrand-Saint Oyant et al. 2018)), except for PM2018 (Rh12GR_34665_95, 45.7 cM, located on chr3 at 41,401,120 bp). On the male map, for the two types of stems and for the three years, the marker with the highest LOD for the QTLs detected on LG3 is the same, Rh12GR_52506_1218 (42.6cM on the LG3, 42,317,122 bp on Chr3), which is the terminal marker on the genetic map but not on the physical map.

Furthermore, if we consider the common 0.95 Bayesian credible interval of these QTLs on LG3 on the female and male maps, all intervals are overlapping (Table 2 and Figure 4). For the female map, the interval on LG3 was 40.38-53.75 cM, which corresponds to the interval $36,517,224-46,440,369$ bp on the physical map of chr3 (Figure 4a), and 
311 for the male map, the interval on LG3 was $37.69-42.55 \mathrm{cM}$, corresponding to the 312 interval 41,648,024-42,317,122 bp on the physical map (Table 2, Figure 4b).

313 On LG4, QTLs were only detected on the female map for the main stem for the three 314 years (Figure 2, Table 2). The peak marker Rh12GR_60129_183 located at 30.6 cM, 315 which is located on chr4 at $52,239,028 \mathrm{bp}$, explained 10.35 to $13.18 \%$ of the observed 316 variance depending on the year of the phenotypic variance in the single QTL model. 317 The common 0.95 credible interval on LG4 was 20.53-48.59 cM, which covered from $31846,189,407-56,107,784$ bp on the physical map (Figure 4a, Table 2).

319 On LG6, QTLs were only detected on the male map for three years for PM and for two 320 years (2017 and 2018) for PF (Figure 2 and Table 2). For PM (2016, 2017 and 2018) 321 and PF (2017), the peak marker is the same, Rh12GR_56601_1304 (29.7 cM, located 322 on chr6 at 31,814,891 bp). For PF2018, the peak marker is Rh88_37299_454 (11.5 cM, 323 located on chr6 at 5,410,244 bp). These QTLs explained between 5.28 and $8.45 \%$ of 324 the observed variance. The common 0.95 credible interval was from 15.59 to $42.49 \mathrm{cM}$, 325 which covered from 8,578,645 to $44,264,630$ bp on the physical map (Figure 4b, Table $3262)$.

327 On LG1, QTLs were only detected on the male map for PF for two years (2016 and 328 2018), and explained 6.52 and $6.99 \%$ of phenotypic variance, respectively. The 329 common 0.95 credible interval was at 12.78-44.11 cM, which covered from $33020,231,658-62,553,371$ bp on the physical map (Figure 4b, Table 2). 
We checked the interaction between OB3@Rh12GR_16570_782 and OB4@Rh12GR_ 60129_183, and between RW3@Rh12GR_52506_1218 and

RW6@Rh12GR_56601_1304, and no significant interaction was detected.

\subsection{Two-part QTL analysis}

335 In order to extend the analysis even further, we performed a two-part QTL analysis to 336 test the penetrance (presence/absence of prickles, $\operatorname{LOD}(p)$ were calculated with binary 337 traits) and the severity (density of prickles on stems with prickles, $\operatorname{LOD}(\mu)$ were 338 calculated with non-zero quantitative phenotype) of these QTLs.

339 For the hypothesis $\operatorname{LOD}(p)$ on the female and male maps, we obtained a significant $340 \operatorname{LOD}(p)$ on the LG3 for the two types of stem (PF and PM) and the three years (Figure 3413 , Supplementary Table 2). The marker with the highest LOD score on the OB map is 342 the same: Rw35C24 (SSR marker) located at 44.4cM (Chr03: 40,215,502 bp). This 343 QTL explained $13.38 \%$ to $16.72 \%$ of the variation. The peak marker on the RW map is 344 also the same for PF and PM for the three years: Rh12GR_52506_1218 located at 42.6 $345 \mathrm{cM}(42,317,122 \mathrm{bp})$. This QTL explained 20.69 to $33.21 \%$ of the variation. These data 346 suggested that the QTL detected on LG3 mainly controls the presence/absence of 347 prickles. Moreover, the $\operatorname{LOD}(p)$ on LG2 and LG6 for the male map were only 348 significant in PF2016 and PM2016, respectively (Figure 3), and they showed a weak 349 effect with an explanation of $1.80 \%$ and $2.70 \%$ of the variance, respectively 350 (Supplementary Table 2).

351 For the $\operatorname{LOD}(\mu)$ hypothesis, we detected a significant QTL on the female map on LG4 352 for PM (2016 and 2017) and PF (2016) (Figure 3, Supplementary Table 2). The QTLs 
explained $9.02 \%$ to $9.88 \%$ of the observed phenotypic variances. Therefore, this QTL might be involved in the control of prickle density. On LG3, a significant QTL was 355 detected on the male map for PM $(2016,2017,2018)$ and PF (2016), suggesting that a QTL on LG3 might also control prickle density. This QTL is in the same region of the peaks in OB (PM2018) and in RW (PF2018) were higher than the genome-wild threshold $(\mu)$; these QTLs explained 6.66\% and 7.80\%, respectively, of prickle density variation.

\section{3- The interaction of the LG3-QTL allele between $O B$ and $R W$}

362 Based on non-parametric and two-part methods, we identified QTLs for the presence 363 of prickles on LG3 for the OB and RW maps in the same region. To further investigate 364 how the alleles on these QTLs affect the presence of prickles, we visualized the number 365 of prickles for each genotype in the hybrid population depending of the Mendelian 366 distribution of the SNP markers at the LOD peak (Figure 5). The female and male 367 alleles are referred to as $a, b$ and $c, d$, respectively. The separation ratio $a c: a d: b c: c d$ in 368 offspring is 33:54:16:48, and was significantly different from the expected segregation 369 of $1: 1: 1: 1(37.5$ for each) with a $p$-value $=0.004$ estimated by a chi-squared test (Figure $3705)$.

371 For PF and PM in all three years, we clearly see that the $b d$ allele combination in hybrids 372 is correlated with no-prickle individuals or individuals with only a few prickles (less 373 than two on four internodes), whereas $a c$, ad and $b c$ genotypes present prickles (Figure 374 5). These results suggest a dominant/recessive model for this QTL with the $b$ and $d$ 
375 alleles linked to the null or recessive alleles (prickless mutant) and the $a$ and $c$ alleles 376 linked to the dominant alleles (prickles). For PM, a co-dominant effect can be detected 377 since the phenotype for $a c$ is significantly different from the one for $a d$ and $b c(a c>a d$

378 and $a c>b c$, p-value $<0.05$, except for PM2016 between $a c$ and $a b$; Figure 5), even if 379 the effect is weak (no large difference between the mean for $a c$ and $a d / b c$ ). For PF, no 380 co-dominant effect was detected.

381 We also observed some odd phenotypes. For instance, OW9067 and OW9068 (red dots) 382 had no prickles and were grouped in the ad genotype, perhaps due to recombination 383 between the marker and the prickle locus (Figure 5). For individuals with the $b d$ 384 genotype, six individuals (blue and green dots) always have prickles: OW9062, 385 OW9021, OW9052 and OW9109 (blue dots) look like the usual prickle genotypes and 386 are probably caused by recombination, but the two extreme exceptions, OW9106 and 387 OW9107 (green dots) with the highest prickle density are not that easy to clarify. 388 Moreover, some individuals exist with both prickly and glabrous stems in the same 389 plant.

\section{3- Candidate genes in the QTL interval region and gene expression analysis}

\subsection{Candidate gene characterization and location in rose.}

392 Since it was proposed that prickles originate from a deformation of glandular trichomes 393 in rose (Kellogg et al. 2011), we looked for rose homologues of transcription factors 394 (TF) known to be involved in the molecular control of trichome initiation and 395 development in Arabidopsis. The information from 15 TFs such as the bHLH (basic 396 helix-loop-helix), C2H2 Zinc-Finger, MYB, WD40 repeat and WRKY families are 
presented in Supplementary Table 3. For a more detailed annotation, we performed 398 phylogenetic analyses on these protein families (Supplementary Figure 3).

399 Concerning the bHLH family (Supplementary Figure 3a), RC7G0190300, 400 RC1G0342400 and RC6G0407800 showed strong similarity with GLABROUS3, 401 MYC1 and TT8, respectively, where all of the proteins are in the same clade. They are 402 referred to as RcGL3, RcMYC1 and RcTT8, respectively.

403 For the C2H2 family, RC3G0150000, RC4G0390900 and RC4G0476500 are closely 404 related to GLABROUS INFLORESCENCE STEMS proteins (GIS, GIS2 and GIS3) 405 and ZINC FINGER PROTEIN (ZFP5, 6 and 8). RC3G0150000 seems to be more 406 closely related to GIS2, RC4G0390900 to GIS3 and RC4G0476500 to ZFP5. 407 RC2G0415300 and RC6G0454700 are related to ZFP1 and ZFP3 and AT5G10970. 408 They are referred to as RcZFP1-like1 and RcZFP1-like2, considering that they are 409 closer to ZFP1 (Supplementary Figure 3b).

410 R2R3 MYB and R3 MYB belong to the MYB family (Supplementary Figure 3c). In 411 the R2R3 MYB sub-family (blue sub-tree), RC7G0156100 is in the same clade as 412 GLABROUS1, whereas RC2G0033100 and RC7G0261400 are more closely related to 413 MYB82 and TT2, respectively. RC3G0322900 is in the same clade as MYB61, MYB50 414 and MYB86. In the R3 MYB sub-family (red sub-tree), RC2G0548400, RC1G0560100 415 and Chrlg0359121 (Raymond et al. 2018) are in the same clade of CPC, TRY, ETC1 416 and ETC3. RC1G0560100 and Chr1g0359121 are more closely related to TRY and 417 CPC, and are referred to as RcTRY and RcCPC, respectively. (Supplementary Figure $418 \quad 3 d)$. 
421 clade.

422 In the WRKY family, as previously shown by Hibrand-Saint Oyant et al. (2018), RC3G0244800 shows a strong similarity with AtTTG2 (TESTATRANSPARENT GLABRA2), whereas RC3G0309600 and RC3G0309700 seem to be more closely related to WRKY54 and WRKY70, RC3G0392200 to WRKY74, and RC3G0414600 appears to be related to WRKY34 and WRKY2.

We then located these rose homologue genes on the rose genome and looked for co428 location between these genes and the QTLs previously described (Figure 4A and B). 429 Concerning the QTLs on LG3 (male and female map, Figure 4a and b), the most interesting TF among the detected genes was RcMYB61 (RC3G0322900, at Chr03: $39,896,892-39,899,077)$ located in the cQTL interval $(36.517-46.440 \mathrm{Mb})$ for the

432 female map (Figure 4A). As previously described (Hibrand-Saint Oyant et al. 2018), a 433 homologue of TTG2, a WRKY transcription factor $(R C 3 G 0244800)$, is also located in the credible interval. RcGIS2 (RC3G015000), a GIS2 homologue is also located on LG3 but not in the cQTL interval. In addition to the candidate TFs, we also scanned the other

436 TFs co-located in the cQTL interval on LG3 of the female map. There are four bHLH, 437 two $\mathrm{C} 2 \mathrm{H} 2$, three R2R3MYB and seven WD40 transcription factors (Supplementary 438 Figure 3, in blue) located under the cQTL.

439 Concerning the cQTL interval on LG4, RcGIS3 is positioned at Chr04: 50,315,805 $44050,317,009(1.21 \mathrm{~Kb})$, and near the peak marker Rh12GR_55601_1304 (52,239,028 
$\mathrm{kb}$ ) on the female map (Figure 4A). RC4G0476500, a ZFP5 homologue, is also located

442 on the female LG4 but not in the QTL interval.

443 Concerning the QTL on the male LG1, RcMYC1, RcTRY and RcCPC, which are 444 positioned at 44,468,298-44,473,643 bp, 47,708,966-47,709,896 bp and 62,070,383$44562,072,848 \mathrm{bp}$, respectively, are located in the cQTL region $(20.232 \mathrm{Mb}-62.553 \mathrm{Mb})$ of 446 PF $(2016,2018)$ on the male LG1. The gene RC1G0586100 (RcTTG1) is also located 447 on LG1 but outside this interval.

448 For the male LG6, RC6G0407800, a homologue of TT8, is not located in the cQTL 449 credible interval, and no studied gene was detected below this QTL.

\subsection{Candidate gene expression in glabrous and prickle roses.}

451 Based on the positional approach, we identified ten interesting candidate genes, six 452 within the QTL interval and the other four outside of QTL but near the credible interval 453 (Figure 4). In order to obtain more information about these genes, we studied their 454 transcript accumulation by RT-qPCR in tissues from prickle (P) and prickless (NP) 455 stems at different developmental stages: I, IIa, IIb, IIc, III (Supplementary Figure 1).

456 The cluster analysis of gene expression clearly showed that all the samples can be 457 divided into two main groups: PI, NPI, PIIa, NPIIa, PIIb, NPIIb were gathered into one 458 group, and PIIc, NPIIc, PIII, NPIII into another group (Figure 6a). At the sup-group 459 level, PI and NPI, PIIa and NPIIa, PIIb and NPIIb, PIIc and NPIIc were clustered 460 together, respectively. At the same stem developmental stage, prickle and glabrous 461 samples (P and NP) behave similarly, suggesting no major difference of transcript 462 accumulation between prickle and glabrous samples; the observed differences are more 
463

closely related to stem development.

To extend the analysis even further, we used NP as a control to compare the normalized expression of genes between P and NP samples in the different stages (Figure 6b). In stage I, two genes are differentially expressed: RcMYB61 and RcGIS2 were downregulated in prickly stems, with a significant p-value $=4.1 \mathrm{e}-5$ and 2.9e-4 (Figure 6b), respectively. In stage IIa, only RcZFP5 was significantly differentially expressed between $\mathrm{P}$ and NP, with a $\mathrm{p}$-value $=0.0056$ and $\mathrm{FC}=-5.7606$ (Figure $6 \mathrm{~b}$ ). A different pattern is observed in stage IIb where RcZFP5 expression was up-regulated with $\mathrm{FC}=$ 8.2240 and a p-value $=0.0025$. In addition, the transcripts of $R c M Y C 1, R c C P C$ and RcGIS2 were also significantly accumulated (p-value $=4.1 \mathrm{e}-5,0.0048,0.0012$, respectively) in stage IIb. In stage IIc, no significant change in gene expression was detected. In stage III, the RcGIS2 transcript is differentially accumulated with $\mathrm{FC}=$ 4.908 and a p-value $=0.043$. The same pattern is observed for RcMYB61 with a pvalue $=4.9 \mathrm{e}-4$

We followed the transcript accumulation during stem development in prickly and glabrous stems (NPI as a control; Figure 6c). All the studied genes are regulated between the different samples. For instance, RcMYB61 is up-regulated and RcMYC1 is down-regulated between the different stages. For RcZFP5, we observed a delay in the decrease of transcript accumulation, with a decrease in stage IIa for glabrous stems and in stage IIb for stems with prickles (Figure 6c).

\section{Discussion}

Two types of prickles are present in the $O W$ progeny, originating from different 
486 A good understanding of prickle morphology is required to serve as the foundation for 487 genetic and molecular studies. We identified two different types of prickles in our 488 population: it appears that GP and NGP originate from glandular and non-glandular 489 structures, respectively. This conclusion is different from previous studies in rose,

490 which reported that prickles were extensions or modifications of glandular trichomes 491 (Kellogg et al. 2011), and in other species (Ma et al. 2016b; Pandey et al. 2018). Asano 492 et al. (2008) observed two types of prickles in the cultivated rose 'Laura', described as 493 large size and small size prickles. The large size prickles look similar to NGPs in our 494 study. The small size prickles, referred to as acicles (Asano et al. 2008), are more 495 closely related to the glandular prickles (GP) we observed since they have a glandular 496 head that accompanies them throughout their lifetime. The difference between these 497 two types of prickles is also related to their segregation in the OW population (Figure 498 1d), demonstrating that different genetic determinisms are involved. In this study, since 499 only a few $F_{1}$ individuals had GPs, we cannot perform a genetic analysis on GPs, we 500 concentrated our analysis on NGPs.

\section{A complex genetic determinism for prickles in rose}

502 Prickles on stems exhibited transgressive segregation in diploid OW, the same as for 503 the tetraploid K5 population (Koning-Boucoiran et al. 2012; Gitonga et al. 2014; 504 Bourke et al. 2018), supporting the hypothesis that multiple loci may be responsible for 505 this trait. 
Using the 'non- parametric' QTL approach, we detected a stable QTL on LG3 in the three different years for both types of stems (PM and PF) on both the male and female genetic maps. We also demonstrated that this QTL mainly controls the presence/absence of prickles (Figure 3) using the 'two-part' QTL method. Interestingly, for PM in males, the QTL on LG3 may also be involved in regulating prickle density

511 (severity in the two-part QTL analysis; Figure 3). A similar phenomenon was observed 512 for the petal number with a locus on LG3 that controls the difference between simple 513 and double petals, and a variance of the petal number that exists within the double petal 514 flower is controlled by another locus (Roman et al. 2015; Hibrand-Saint Oyant et al. 515 2018).

516 We further enhanced the description of QTLs on LG3 that affect the presence/absence 517 of prickles. A significantly distorted segregation was observed at the peak marker 518 position. That unusual segregation ratio might be explained by the presence of a self519 incompatibility locus (Hibrand-Saint Oyant et al. 2018) near the peak marker for this 520 QTL. On the basis of the phenotype-genotype relationship (Figure 5), we proposed that 521 the PRICKLE alleles on this QTL are both heterozygous (np/P) in OB and RW, and that 522 the presence of prickles is controlled by a dominant allele (np/P or $\mathrm{P} / \mathrm{P})$, and that the 523 glabrous stem in the progeny is due to the combination of the two recessive alleles 524 coming from both parents (np/np). These results are important for breeders who need 525 to combine recessive alleles to obtain glabrous roses, an allelic combination that can be 526 difficult in tetraploid roses. Development of specific molecular markers of the recessive 527 allele may by useful for breeders. However, it should be noted that the actual markers 
used (peak of the QTL) are only closely linked to the PRICKLE locus and few recombinants are observed in the progeny. Furthermore, the phenotype of the

530 individuals with the two recessive alleles ( $b d$ phenotype; Figure 5) are not stable and

531 some of the hybrids were regularly seen to develop some prickles on parts of the stems.

532 Indeed, this phenomenon is widespread in roses. Rose breeders have reported that 533 glabrous mutants have either been unstable for the prickless trait (Nobbs 1984; Rosu et 534 al. 1995), or reverted to the prickly character after a freezing winter or other 535 environmental stresses (Nobbs 1984; Oliver 1986; Druitt and Shoup 1991; Canli 2003). 536 Taken together, we assumed that a single major locus on LG3 controlled the 537 absence/presence of stem prickles. Further investigations are necessary to more closely 538 identify molecular markers (for molecular assisted breeding) and the mechanisms 539 behind the instability.

540 In the $a c, a d$ and $b c$ genotypes, each genotype has a continuous quantitative trait, 541 indicating that there are other loci responsible for prickle density variance. Other QTLs 542 affecting quantitative traits were detected on LG4 in OB and on LG1 and 3 in RW (Two543 part QTL analysis; Figure 3). The LG4 QTL has a strong effect on PM but a weak effect 544 on PF. For the QTL on LG1, it only had a weak effect on PF and on PM in 2018. Those 545 three loci are related to the density of prickles, indicating that there are multiple genes 546 responsible for the density trait, and that those genes have a different effect on the 547 different stems.

Detected QTLs are conserved in the Rosa genus and the Rosideae subfamily

549 Thanks to the link between genetic maps and reference genome sequences (Hibrand- 
550 Saint Oyant et al. 2018), we were able to compare our results with previous genetic 551 studies by associating genetic map markers.

552 A QTL was previously detected on LG3 in different diploid and tetraploid populations

553 (Crespel et al. 2002; Linde et al. 2006; Koning-Boucoiran et al. 2012; Hibrand-Saint 554 Oyant et al. 2018 ; Bourke et al. 2018), which is consistent with our results: a strong 555 QTL on Chr3 with a high LOD value was detected in all of the environments (across 556 and between years and types of stems). This demonstrated that Chr3 QTL is a robust 557 QTL detected independently of ploidy and the environment, and is present in various 558 genetic backgrounds.

559 Recently, three QTLs on LG3, 4 and 6 were detected in the tetraploid K5 population 560 with a high density of SNPs genetic map (Bourke et al. 2018). Interestingly, the QTLs 561 identified from the diploid (OW) were almost identical to tetraploid (K5) populations 562 (LG3, 4 and 6), with the slight difference that we also detected a weak QTL on LG1, 563 which was only significant in males for two of the years. This slight difference might 564 be due to the genetic background of the parents of the $\mathrm{K} 5$ and $\mathrm{OW}$ populations. In 565 fact, in K5 populations, one parent is prickly and the other glabrous, whereas in OW 566 populations, both parents have prickles. Bourke et al. (2018) reported that two SNP 567 markers, K7826_576 (located on the Chr3: 37,706,920 pb) and K5629_995 (located on 568 the Chr4: 57,791,999 bp) are linked to the stem prickle trait. When compared with our 569 results, K7826_576 is located within our Chr3 cQTL interval region (36,517,224$57046,440,369$ bp; Figure 4), and K5629_995 is very close to our Chr4 QTL interval $571(46,189,407-56,107,784 \mathrm{bp})$. These results suggest that QTLs detected on LG3 and 4 
could be similar between OW and K5 progenies.

In Rosaceae, the genetic determinism of prickle was studied in raspberry (Rubus idaeus), where two QTLs were detected on LG4 and 6 (Molina-Bravo et al. 2014). Using synteny viewer tools (https://www.rosaceae.org/synview/search; Jung et al. 2014), we checked the synteny. The region where the QTL is located on LG6 in $R$. occidentalis (position $6,028 \mathrm{Mb}$ ) is syntenic with a region on rose chromosome 2 (position 42,330 Mb), where no QTL for prickle density was detected in our study. The region where the QTL 4 is located (position $0.101 \mathrm{Mb}$ ) is syntenic with the region on rose chromosome 4 (position 58,768 Mb), very close to the main QTL we detected on this chromosome (Table 2). These results could suggest that the two QTLs in rose and raspberry might be syntenic and share a common evolutionary history. In another publication, Graham et al. (2006) identified the gene $H$ that controls cane pubescence. The locus is mapped on LG2, which is syntenic with the rose LG6 where one of the QTLs is located, detected in R. $x$ wichurana. However, no precise location is available to allow us to assume a possible common origin.

\section{Candidate gene below the QTL interval region}

Prickles are assumed to originate from a 'trichome-like structure'. In order to find a putative candidate gene for the identified QTLs, we looked for homologue genes known to be involved in trichome initiation and development in Arabidopsis. We annotated 15 rose TFs that, based on similarity, can be involved in trichome development in rose: RcGL1, RcMYB82, RcMYB61, RcCPC, RcTRY, RcGL3, RcTT8, RcMYC1, RcTTG1, RcTTG2, RcZFP5, RcGIS3, RcGIS2, RcZFP1 and RcGL2 (Table 3). Among them, a 
594 few were below the detected QTLs: RcMYB61 and RcTTG2 below the QTL on LG3;

595 RcGIS3 below the QTL on LG4; and RcCPC, RcTRY and RcMYC1 below the QTL on

596 LG1. ZFP5 (Chr04: 57,125,905 bp) is out of the QTL interval on LG4 in OW, but close

597 to the peak LOD marker K5629_995 of QTL in the K5 population (Chr04: 57,791,999

598 bp) (Bourke et al. 2018). These genes are good candidates for the detected QTLs.

599 Candidate genes transcript expression in glabrous and prickle $F_{1}$ individuals

600 We quantified ten TF gene transcripts in glabrous and prickle $F_{1}$ individuals in different

601 developmental stages using RT-qPCR. Surprisingly, minor differences were observed

602 between glabrous and prickle samples, with the main differences occurring between

603 developmental stages (as demonstrated by the heatmap analysis, Figure 6a). Based on

604 transcript accumulation, this suggests that these homologues, known to be involved in

605 trichome initiation and development in Arabidopsis, are not implicated in prickle

606 initiation in rose, leading to the hypothesis that the two processes (trichome initiation

607 and prickle initiation) might involve different gene pathways. The candidate gene

608 approach may not be appropriate and a non-a priori approach such as a transcriptomic

609 analysis could be done between individuals with and without prickles.

610 Nevertheless, some differences in transcript accumulation are observed between

611 candidate genes. In the early stage (stage I), only RcMYB61 and RcGIS2 are slightly

612 more highly accumulated in glabrous stems. However, GIS2 and MYB61 are positive

613 regulators of trichome initiation (Gan et al. 2006), which is difficult to reconcile with

614 an increase in transcript accumulation in glabrous stems (Figure 6). Negative feedback 
regulation during prickle initiation can explain this point, as regularly observed in trichome initiation (Pattanaik et al. 2014) or, perhaps, differences are not at the

617 transcriptional level. It could be interesting to sequence the genes in the two parents to 618 see if a mutation can explain the phenotype.

619 RcZFP5 may also be an interesting candidate gene. This gene showed a different 620 regulation between glabrous and prickly stems. At stage IIa, RcZFP5 shows a strong 621 down-regulation in glabrous tissue, whereas this down-regulation is observed later at 622 stage IIc in tissues with prickles (Figure 6C). Furthermore, this gene is close to the QTL 623 on LG4. Its early repression in glabrous stems might explain why no prickles developed. 624 In A. thaliana, ZFP5 controls trichome initiation through GA signaling (Zhou et al. 625 2011). These data (concerning ZFP5 and MYB61) might suggest an implication of GA 626 in prickle development. However, this hypothesis needs to be functionally validated in 627 rose.

\section{Conclusion}

629 Prickle structure is an undesirable trait, not only in rose but in most crops in general.

630 We identified a complex genetic determinism with a major locus on LG3 that controls 631 the presence of prickles and a few QTLs that control prickle density. Further studies are 632 necessary to develop markers for breeding selection and to identify the molecular bases. 633 Using a candidate gene approach, we proposed different hypotheses concerning the 634 gene involved in prickle initiation in rose. Approaches such as transcriptomics may help to identify new key regulators of prickle initiation and development in rose. 


\section{Acknowledgements}

637 We are grateful to the experimental unit (UE Horti) for their technical assistance in 638 plant management, and the ImHorPhen team (D. Besnard, R. Gardet) of IRHS for 639 taking care of the plant cuttings in the greenhouse. We would also like to thank the 640 IMAC technical platforms (F. Simonneau, A. Rolland) of SFR Quasav for supervising 641 the histological experiment, and the PTM ANAN (M. Bahut) of the SFR Quasav for 642 overseeing the RT-qPCR experiment. We acknowledge J. Chameau of the GDO team 643 for helping to obtain the different stages of the sample.

644 This work was supported by funding from the National Natural Science Foundation of 645 China (31760585), the China Scholarship Council ([2017]3109) and the Natural 646 Science Foundation of Yunnan (2016FB061).

\section{$647 \quad$ Figure legends}

648 Figure 1 Different types of prickles on the OW progeny stem and their distribution. (a)

649 Stem prickles in the female 'Old Blush' (OB) and the male $R$. $x$ wichurana $(\mathrm{RW})$; NGPs:

650 non-glandular prickles. (b) Stem prickles in $F_{1}$ progeny. Glabrous: no prickles 651 whatsoever on the recorded stems in the three years. (c) Macroscopic photos of the 652 terminal part of the stems with different types of prickles (number of offspring); GPs: 653 glandular prickles. (d) The distribution and Q-Q plot of NGPs and GPs in the F $_{1}$ 654 progeny in 2018; PF: prickles on the floral stem; PM: prickles on the main stem.

655 Figure 2 LOD curves of the QTL scan for the NGPs on the floral (FM) and main (PM) 656 stems in (a) female (OB) and (b) male map (RW) calculated with a non-parametric 657 model for the three years (2016, 2017 and 2018, with red, blue and green lines, 
respectively). The LOD threshold value is represented by a dotted line in red, blue and green for 2016, 2017 and 2018, respectively.

Figure 3 LOD curves of the QTL scan for the NGPs on the floral (FM) and main (PM) stems in (a) female (OB) and (b) male (RW) maps calculated using the two-part approach. The LOD (p) value (penetrance) is in red, the LOD $(\mu)$ value (severity) is in blue, and the $\operatorname{LOD}(\mathrm{p}, \mu)$ value is in black. The dotted line represents the LOD threshold. QTLs above threshold value are indicated by stars: red for penetrance, blue for severity. Figure 4 Common QTLs (cQTLs) and candidate genes in (a) the female linkage groups 3 and 4, and (b) the male linkage groups 1,3 and 6. Areas highlighted in pink, blue and yellow on the linkage groups represent the 0.95 Bayesian interval of cQTL for specific PF, PM and both, respectively. Bars and lines on the right of each chromosome represent 0.95 and 0.99 Bayesian intervals of the QTL with a different color for NGPs on the floral stem and the main stem (pink and blue, respectively). The red markers are the peak of the QTL. Brown markers are SSR markers and black markers are SNP markers.

Figure 5 The interaction of the different alleles of the LG3 QTL between OB and RW. Genotype: $a c, a d, b c, b d$ (number of individuals), $a / b$ and $c / d$ alleles belong to females and males, respectively. For the phenotype, the mean values of prickle density for PF and PM for the three years are presented. Some individuals are highlighted with green dots (OW9106 and OW9107), blue dots (OW9062, OW9021, OW9052 and OW9109) and red dots (OW9067 and OW9068). The asterisk indicates that the difference is significant with a p-value of less than 0.05 
Figure 6 Transcript accumulation of candidate genes followed by qPCR during prickle

681

682

683

684

685

686

687

688

689

690

691

692

693

694

695

696

697

698

699

700

701

development. (a) A heatmap of samples and genes. (b) The scatter plot of the candidate genes' normalized expression in prickle and glabrous individuals in different stages (as defined in Supplementary Figure 1). The red and green lines represent a two-fold change in the accumulation with an increase or a decrease, respectively. Gene transcripts differentially accumulated $(\mathrm{p}$-value $<0.05)$ are represented by red or green dots for up- or down-accumulation, respectively. (c) Transcript accumulation in the different stages of prickle (P) and glabrous (NP) stems with NPI as a control.

\section{Electronic Supplementary Material}

Supplementary Figure 1 Stem development and sampling stages in (a) non-glandular prickles (NGP, OW9137), (b) glandular prickles (GP, OW9106), and (c) glabrous stems (NP, OW9068). For the glabrous stems, the developmental stages correspond to the stages for the stem with prickles.

Supplementary Figure 2 Frequency distribution and Q-Q plot of non-glandular prickles on four internodes in the OW population for floral stems (PF) and the main stem (PM) for the three years $(2016,2017$ and 2018).

Supplementary Figure 3 Phylogenetic analysis of the transcription factor family involved in trichome initiation and development: (a) bHLH, (b) C2H2 Zinc-Finger, (c) MYB: R3MYB (red sub-tree) and R2R3MYB (blue sub-tree), and (d) WD40. The rose genes homologues of genes involved in trichome initiation and development are in red.

For A. thaliana, the protein name corresponds to the TAIR database (https://www.arabidopsis.org/), and for rose, to the reference genome of the haploid of 
'Old Blush' (Hibrand-Saint Oyant et al. (2018)), except for Chr1g0359121 and Chr2g0138951 (Raymond et al. 2018).

Supplementary Table 1 Primer sequences of candidate genes for qPCR

Supplementary Table 2 Summary of QTLs for NGPs using the two-part QTL model in OW progeny

Supplementary Table 3 Summary of the rose homologous genes known in A. thaliana to be involved in trichome initiation

Supplementary Table 4 Prickle number on four internodes of two types of stems for the three years in OW progeny.

\section{References}

Asano G, Kubo R, Tanimoto S (2008) Growth, structure and lignin localization in rose prickle. Bull. Fac. Agr., Sagai Univ. 93:117-125

Balkunde R, Pesch M, Hülskamp M (2010) Chapter ten - trichome patterning in Arabidopsis thaliana: from genetic to molecular models. In: Timmermans MCP (ed) Current Topics in Developmental Biology. Academic Press, pp 299-321

Bourke PM, Gitonga VW, Voorrips RE, et al (2018) Multi-environment QTL analysis of plant and flower morphological traits in tetraploid rose. Theor Appl Genet 131:2055-2069. https://doi.org/10.1007/s00122-018-3132-4

Boyartchuk VL, Broman KW, Mosher RE, et al (2001) Multigenic control of Listeria monocytogenes susceptibility in mice. Nat Genet 27:259-260. https://doi.org/10.1038/85812

Broman KW (2003) Mapping quantitative trait loci in the case of a spike in the phenotype distribution. Genetics 163:1169-1175

Burns KC (2014) Are there general patterns in plant defence against megaherbivores? Biol J Linn Soc 111:38-48. https://doi.org/10.1111/bij.12181

Canli FA (2003) A review on thornless roses. Pak J Biol Sci 6:1712-1719 
Canli FA, Kazaz S (2009) Biotechnology of roses: progress and future prospects. Türkiye Orman Derg 10:167-183

Canli FA, Skirvin RM (2003) Separation of thornless rose chimeras into their (Rosa $s p$.) consistent genotypes in vitro. Pak J Biol Sci 6:1644-1648

Chopra D, Mapar M, Stephan L, et al (2019) Genetic and molecular analysis of trichome development in Arabis alpina. Proc Natl Acad Sci 116:1207812083. https://doi.org/10.1073/pnas.1819440116

Crespel L, Chirollet M, Durel C, et al (2002) Mapping of qualitative and quantitative phenotypic traits in Rosa using AFLP markers. Theor Appl Genet 105:12071214. https://doi.org/10.1007/s00122-002-1102-2

Debener T (1999) Genetic analysis of horticulturally important morphological and physiological characters in diploid roses. Gartenbauwissenschaft 64:14-20

Druitt L, Shoup M (1991) Thornless roses. Horticulture, 69:78-82.

Gan Y, Kumimoto R, Liu C, et al (2006) GLABROUS INFLORESCENCE STEMS modulates the regulation by gibberellins of epidermal differentiation and shoot maturation in Arabidopsis. Plant Cell 18:1383-1395. https://doi.org/10.1105/tpc.106.041533

Gan Y, Liu C, Yu H, Broun P (2007) Integration of cytokinin and gibberellin signalling by Arabidopsis transcription factors GIS, ZFP8 and GIS2 in the regulation of epidermal cell fate. Development 134:2073-2081. https://doi.org/10.1242/dev.005017

Gitonga VW, Koning-Boucoiran CF, Verlinden K, et al (2014) Genetic variation, heritability and genotype by environment interaction of morphological traits in a tetraploid rose population. BMC Genet 15:146. https://doi.org/10.1186/s12863-014-0146-Z

Graham J, Smith K, Tierney I, et al (2006) Mapping gene $H$ controlling cane pubescence in raspberry and its association with resistance to cane botrytis and spur blight, rust and cane spot. Theor Appl Genet 112:818-831. https://doi.org/10.1007/s00122-005-0184-Z

Hibrand-Saint Oyant L, Ruttink T, Hamama L, et al (2018) A high-quality genome sequence of Rosa chinensis to elucidate ornamental traits. Nat Plants 4:473. https://doi.org/10.1038/s41477-018-0166-1

Huchelmann A, Boutry M, Hachez C (2017) Plant glandular trichomes: natural cell factories of high biotechnological Interest. Plant Physiol 175:6-22. https://doi.org/10.1104/pp.17.00727 
Ishida T, Kurata T, Okada K, Wada T (2008) A genetic regulatory network in the development of trichomes and root hairs. Annu Rev Plant Biol 59:365-386. https://doi.org/10.1146/annurev.arplant.59.032607.092949

Jung S, Ficklin SP, Lee T, et al (2014) The Genome Database for Rosaceae (GDR): year 10 update. Nucleic Acids Res 42:D1237-D1244. https://doi.org/10.1093/nar/gkt1012

Kawamura K, Oyant LH-S, Crespel L, et al (2011) Quantitative trait loci for flowering time and inflorescence architecture in rose. Theor Appl Genet 122:661-675. https://doi.org/10.1007/s00122-010-1476-5

Kellogg AA, Branaman TJ, Jones NM, et al (2011) Morphological studies of developing Rubus prickles suggest that they are modified glandular trichomes. Botany 89:217-226. https://doi.org/10.1139/b11-008

Kim SY, Hyoung S, So WM, Shin JS (2018) The novel transcription factor TRP interacts with ZFP5, a trichome initiation-related transcription factor, and negatively regulates trichome initiation through gibberellic acid signaling. Plant Mol Biol 96:315-326. https://doi.org/10.1007/s11103-018-0697-x

Kirik V, Lee MM, Wester K, et al (2005) Functional diversification of MYB23 and GL1 genes in trichome morphogenesis and initiation. Development 132:14771485. https://doi.org/10.1242/dev.01708

Koning-Boucoiran CFS, Dolstra O, van der Linden CG, et al (2009) Specific mapping of disease resistance genes in tetraploid cut roses. Acta Hortic 836:137-142. https://doi.org/10.17660/ActaHortic.2009.836.19

Koning-Boucoiran CFS, Gitonga VW, Yan Z, et al (2012) The mode of inheritance in tetraploid cut roses. Theor Appl Genet 125:591-607. https://doi.org/10.1007/s00122-012-1855-1

Li H, Liu FL, Lin X, et al (2012) Studies on anatomical structure and chemical composition in prickles of Rosa hybrida. Acta Hortic Sin 39:1321-1329

Linde M, Hattendorf A, Kaufmann H, Debener Th (2006) Powdery mildew resistance in roses: QTL mapping in different environments using selective genotyping. Theor Appl Genet 113:1081-1092. https://doi.org/10.1007/s00122-006-03672

Ma D, Hu Y, Yang C, et al (2016a) Genetic basis for glandular trichome formation in cotton. Nat Commun 7:1-9. https://doi.org/10.1038/ncomms 10456 
Ma Z-Y, Wen J, Ickert-Bond SM, et al (2016b) Morphology, structure, and ontogeny of trichomes of the grape genus (Vitis, Vitaceae). Front Plant Sci 7:704. https://doi.org/10.3389/fpls.2016.00704

Maes L, Inzé D, Goossens A (2008) Functional specialization of the TRANSPARENT TESTA GLABRA1 network allows differential hormonal control of laminal and marginal trichome initiation in Arabidopsis rosette leaves. Plant Physiol 148:1453-1464. https://doi.org/10.1104/pp.108.125385

Matías-Hernández L, Jiang W, Yang K, et al (2017) AaMYB1 and its orthologue AtMYB61 affect terpene metabolism and trichome development in Artemisia annua and Arabidopsis thaliana. Plant J 90:520-534. https://doi.org/10.1111/tpj.13509

Molina-Bravo R, Fernandez GE, Sosinski BR (2014) Quantitative trait locus analysis of tolerance to temperature fluctuations in winter, fruit characteristics, flower color, and prickle-free canes in raspberry. Mol Breed 33:267-280. https://doi.org/10.1007/s11032-013-9947-4

Nobbs KJ (1984) American Rose Annual. In: Shreveport (ed) Breeding thornless roses. The American Rose Society, pp 37-43

Oliver WG (1986) A précis of thornless development. The rose. The Royal National Rose Society, 80(3).

Pandey S, Goel R, Bhardwaj A, et al (2018) Transcriptome analysis provides insight into prickle development and its link to defense and secondary metabolism in Solanum viarum Dunal. Sci Rep 8:1-12. https://doi.org/10.1038/s41598-01835304-8

Patra B, Pattanaik S, Yuan L (2013) Ubiquitin protein ligase 3 mediates the proteasomal degradation of GLABROUS 3 and ENHANCER OF GLABROUS 3, regulators of trichome development and flavonoid biosynthesis in Arabidopsis. Plant J 74:435-447. https://doi.org/10.1111/tpj.12132

Pattanaik S, Patra B, Singh SK, Yuan L (2014) An overview of the gene regulatory network controlling trichome development in the model plant, Arabidopsis. Front Plant Sci 5:259. https://doi.org/10.3389/fpls.2014.00259

Pesch M, Dartan B, Birkenbihl R, et al (2014) Arabidopsis TTG2 regulates TRY expression through enhancement of activator complex-triggered activation. Plant Cell 26:4067-4083. https://doi.org/10.1105/tpc.114.129379 
Pesch M, Hülskamp M (2004) Creating a two-dimensional pattern de novo during Arabidopsis trichome and root hair initiation. Curr Opin Genet Dev 14:422427. https://doi.org/10.1016/j.gde.2004.06.007

Randoux M, Jeauffre J, Thouroude T, et al (2012) Gibberellins regulate the transcription of the continuous flowering regulator, $R o K S N$, a rose TFL1 homologue. J Exp Bot 63:6543-6554. https://doi.org/10.1093/jxb/ers310

Raymond O, Gouzy J, Just J, et al (2018) The Rosa genome provides new insights into the domestication of modern roses. Nat Genet 50:772-777. https://doi.org/10.1038/s41588-018-0110-3

Rerie WG, Feldmann KA, Marks MD (1994) The GLABRA2 gene encodes a homeo domain protein required for normal trichome development in Arabidopsis. Genes Dev 8:1388-1399. https://doi.org/10.1101/gad.8.12.1388

Roccia A, Oyant LH-S, Cavel E, et al (2019) Biosynthesis of 2-Phenylethanol in rose petals is linked to the expression of one allele of RhPAAS. Plant Physiol 179:1064-1079. https://doi.org/10.1104/pp.18.01468

Roman H, Rapicault M, Miclot AS, et al (2015) Genetic analysis of the flowering date and number of petals in rose. Tree Genet Genomes 11:85. https://doi.org/10.1007/s11295-015-0906-6

Ronel M, Lev-Yadun S (2012) The spiny, thorny and prickly plants in the flora of Israel. Bot J Linn Soc 168:344-352. https://doi.org/10.1111/j.10958339.2011.01211.x

Rosu A, Skirvin RM, Bein A, et al (1995) The development of putative adventitious shoots from a chimeral thornless rose (Rosa multiflora Thunb. ex J. Murr.) in vitro. J Hortic Sci 70:901-907. https://doi.org/10.1080/14620316.1995.11515365

Shupert DA, Byrne DH, Brent Pemberton H (2007) Inheritance of flower traits, leaflet number and prickles in roses. Acta Hortic 751:331-335. https://doi.org/10.17660/ActaHortic.2007.751.42

Symonds VV, Hatlestad G, Lloyd AM (2011) Natural allelic variation defines a role for ATMYC1: trichome cell fate determination. PLOS Genet 7:e1002069. https://doi.org/10.1371/journal.pgen.1002069

Traw MB, Bergelson J (2003) Interactive effects of jasmonic acid, salicylic acid, and gibberellin on induction of trichomes in Arabidopsis. Plant Physiol 133:13671375. https://doi.org/10.1104/pp.103.027086 
865

866

867

868

869

870

871

872

873

874

875

876

877

878

879

880

881

882

883

884

885

886

887

888

889

890

Wang S, Chen J-G (2014) Regulation of cell fate determination by single-repeat R3 MYB transcription factors in Arabidopsis. Front Plant Sci 05:133. https://doi.org/10.3389/fpls.2014.00133

Wang S, Hubbard L, Chang Y, et al (2008) Comprehensive analysis of single-repeat R3 MYB proteins in epidermal cell patterning and their transcriptional regulation in Arabidopsis. BMC Plant Biol 8:81. https://doi.org/10.1186/14712229-8-81

Wester K, Digiuni S, Geier F, et al (2009) Functional diversity of R3 single-repeat genes in trichome development. Development 136:1487-1496. https://doi.org/10.1242/dev.021733

Young MA (2007) Modern roses 12: The comprehensive list of roses in cultivation or of historical or botanical importance. Shreveport: The American Rose Society

Zhang F (2003) A network of redundant bHLH proteins functions in all TTG1dependent pathways of Arabidopsis. Development 130:4859-4869. https://doi.org/10.1242/dev.00681

Zhao H, Wang X, Zhu D, et al (2012) A single amino acid substitution in IIIf subfamily of basic Helix-Loop-Helix transcription factor AtMYC1 leads to trichome and root hair patterning defects by abolishing its interaction with partner proteins in Arabidopsis. J Biol Chem 287:14109-14121. https://doi.org/10.1074/jbc.M111.280735

Zhou Z, An L, Sun L, et al (2011) Zinc finger protein5 is required for the control of trichome initiation by acting upstream of zinc finger protein8 in Arabidopsis. Plant Physiol 157:673-682. https://doi.org/10.1104/pp.111.180281

Zhou Z, Sun L, Zhao Y, et al (2013) Zinc Finger Protein 6 (ZFP6) regulates trichome initiation by integrating gibberellin and cytokinin signaling in Arabidopsis thaliana. New Phytol 198:699-708. https://doi.org/10.1111/nph.12211 
a.

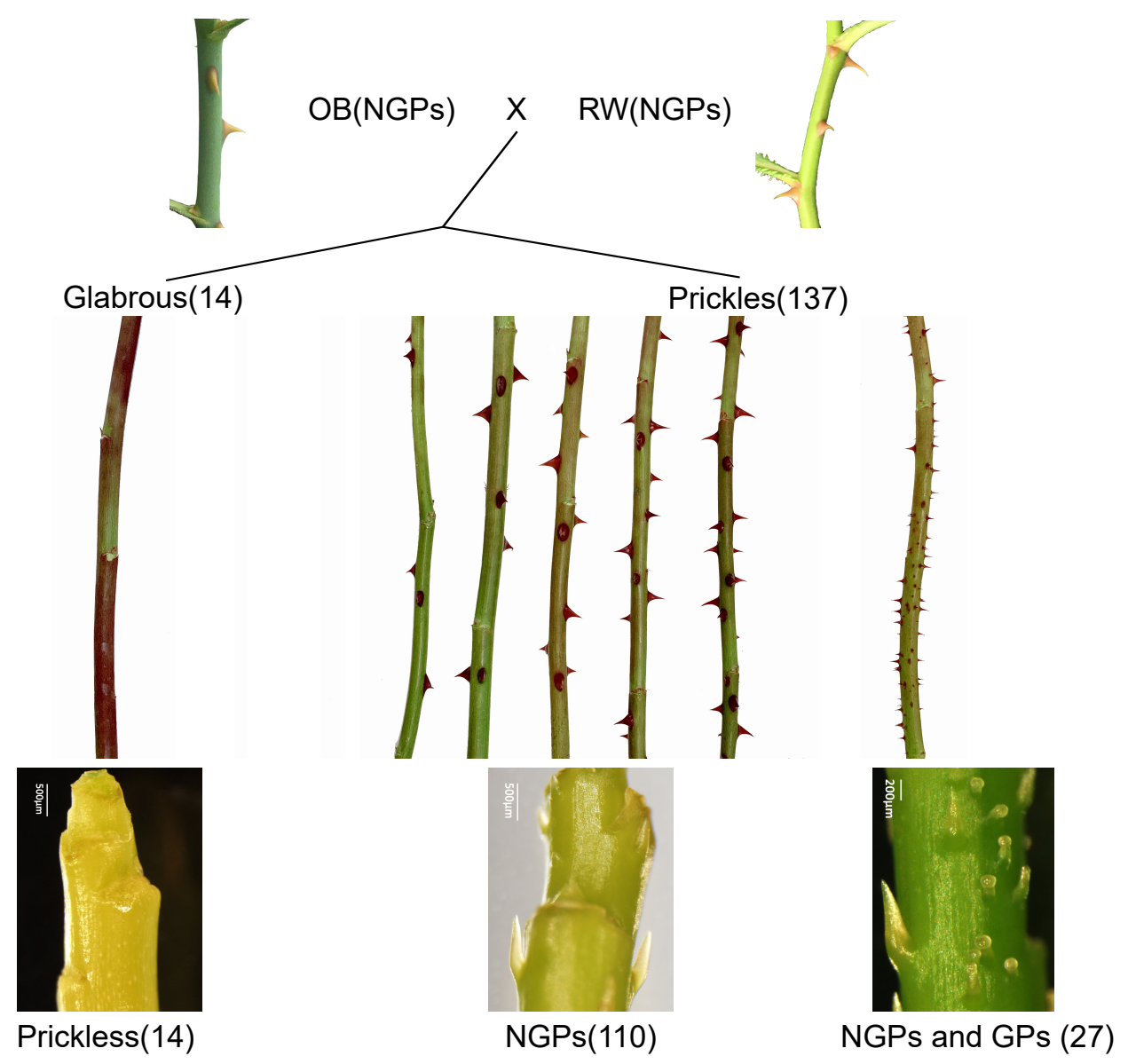

d.
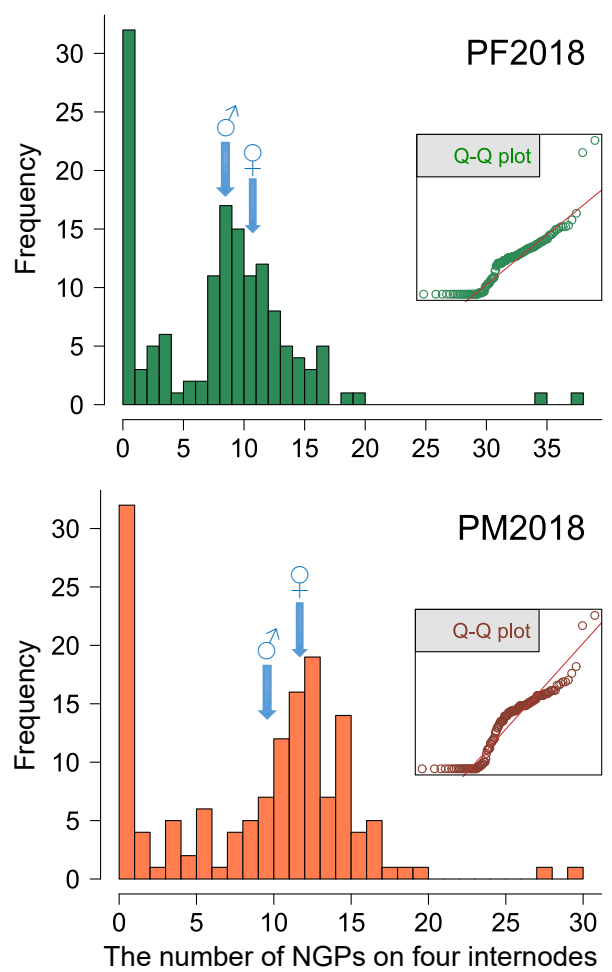
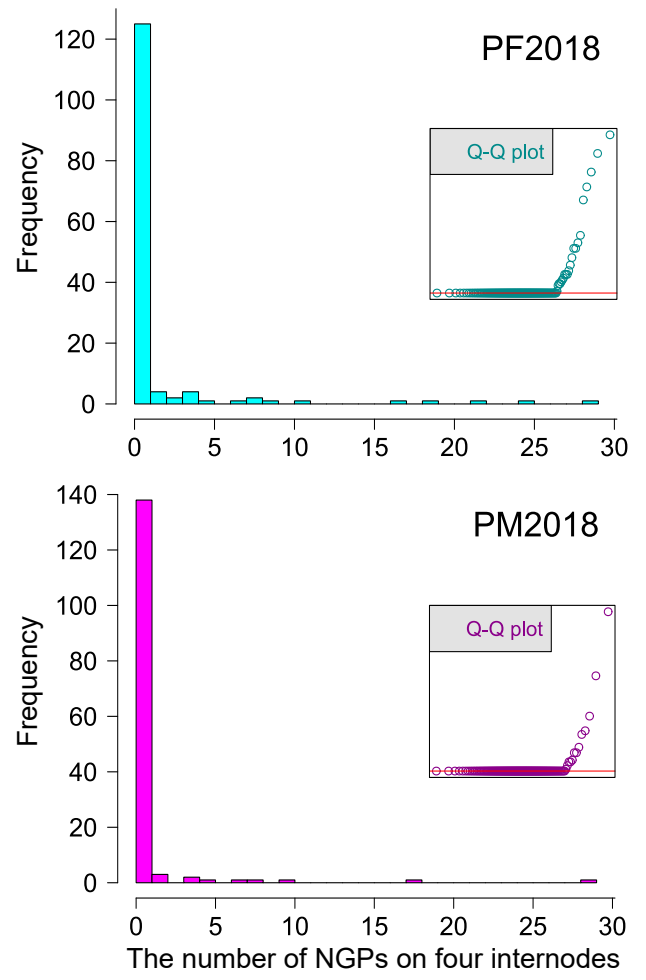

Figure 1 
a.

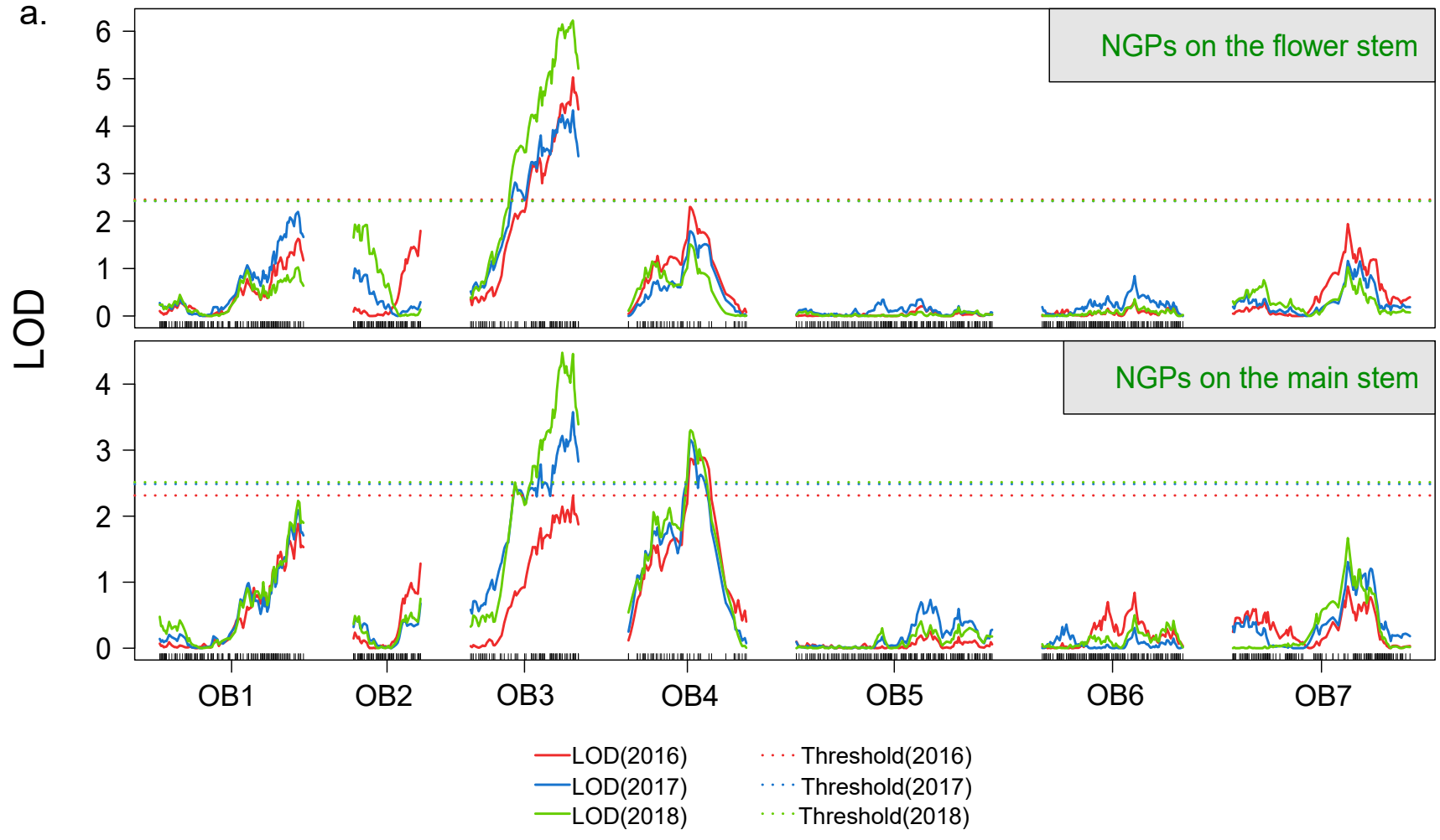

b.

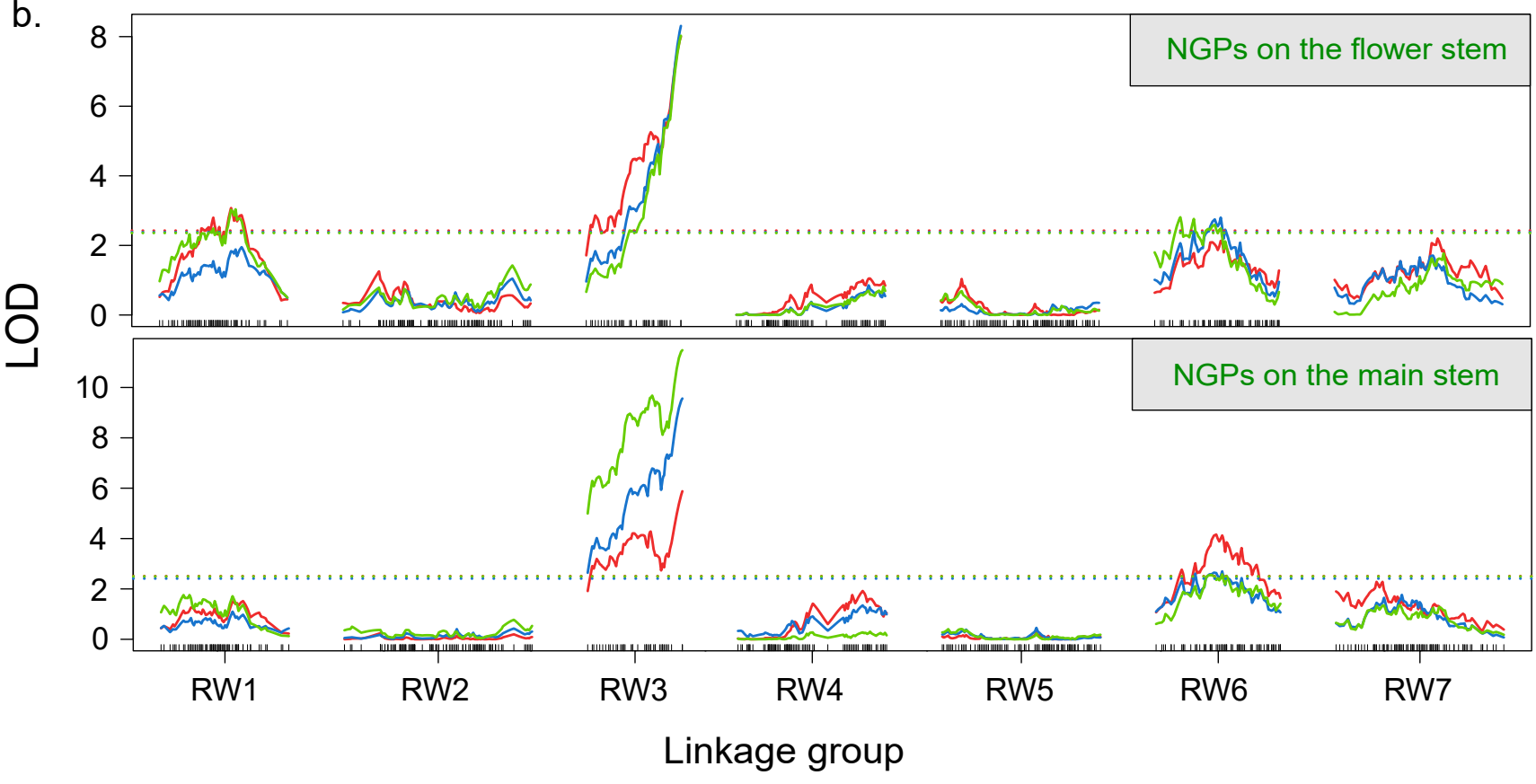

Figure 2 
a.
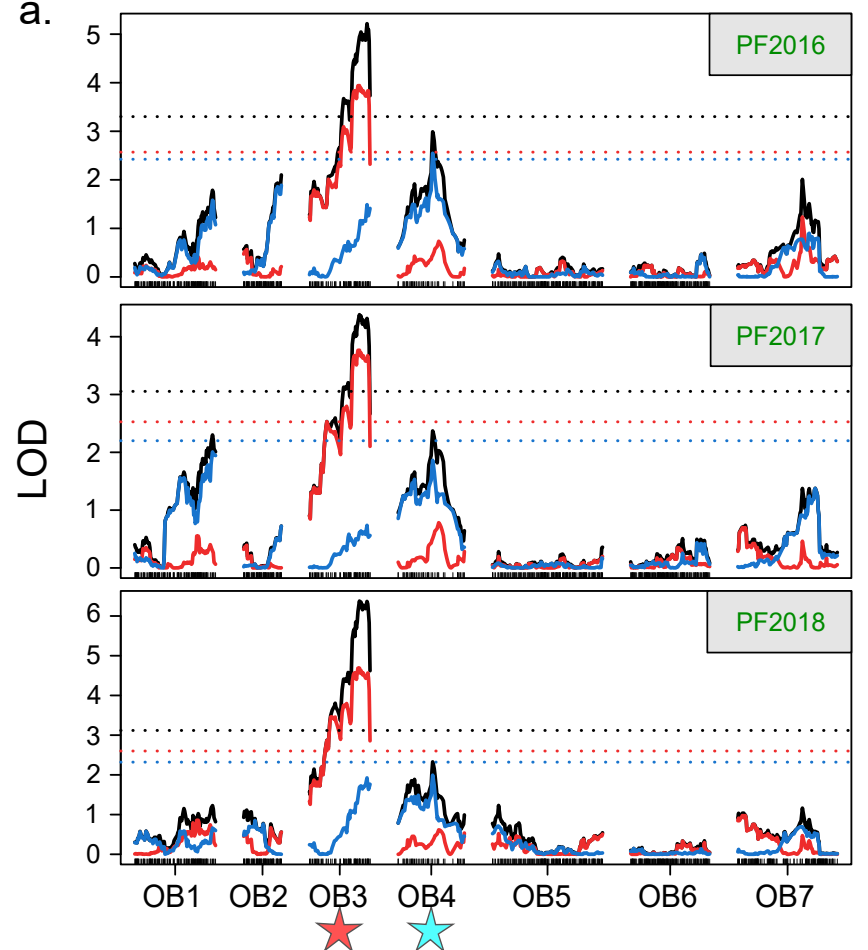

- $\operatorname{LOD}(p, \mu)$

- $\operatorname{LOD}(\mu)$

b.

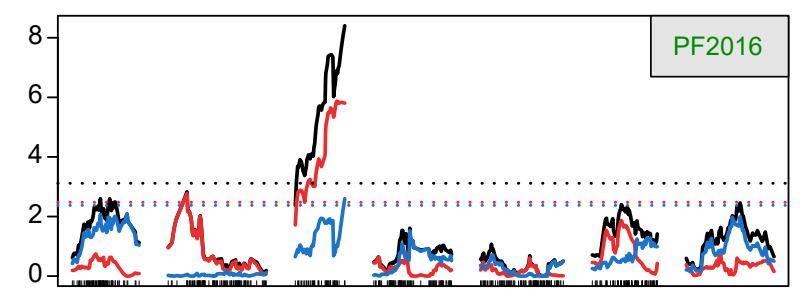

。
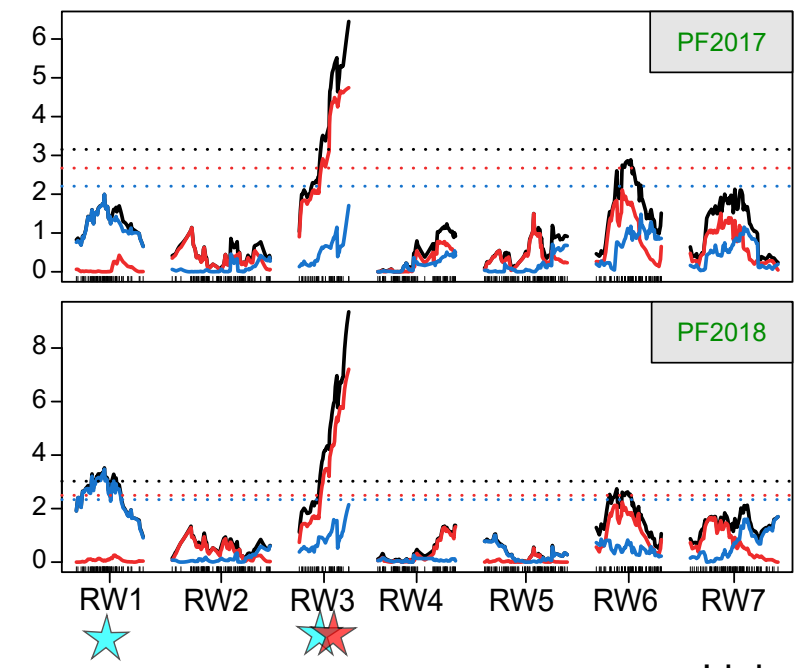

Linkage group
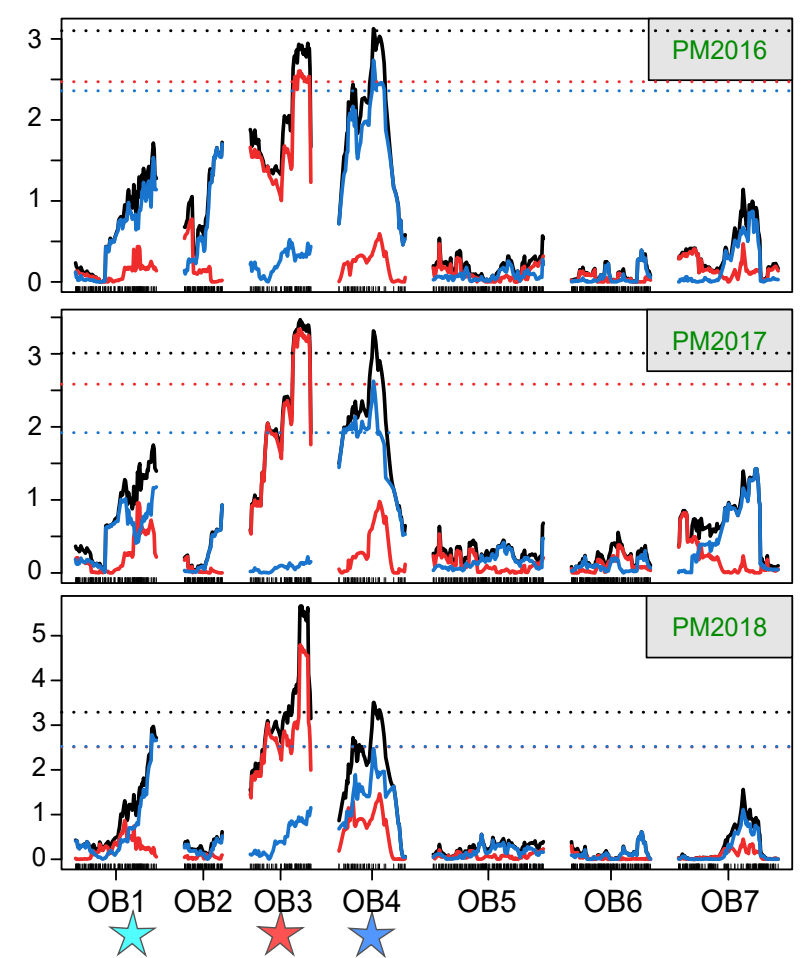

… Threshold $(p, \mu)$
… Threshold $(p)$
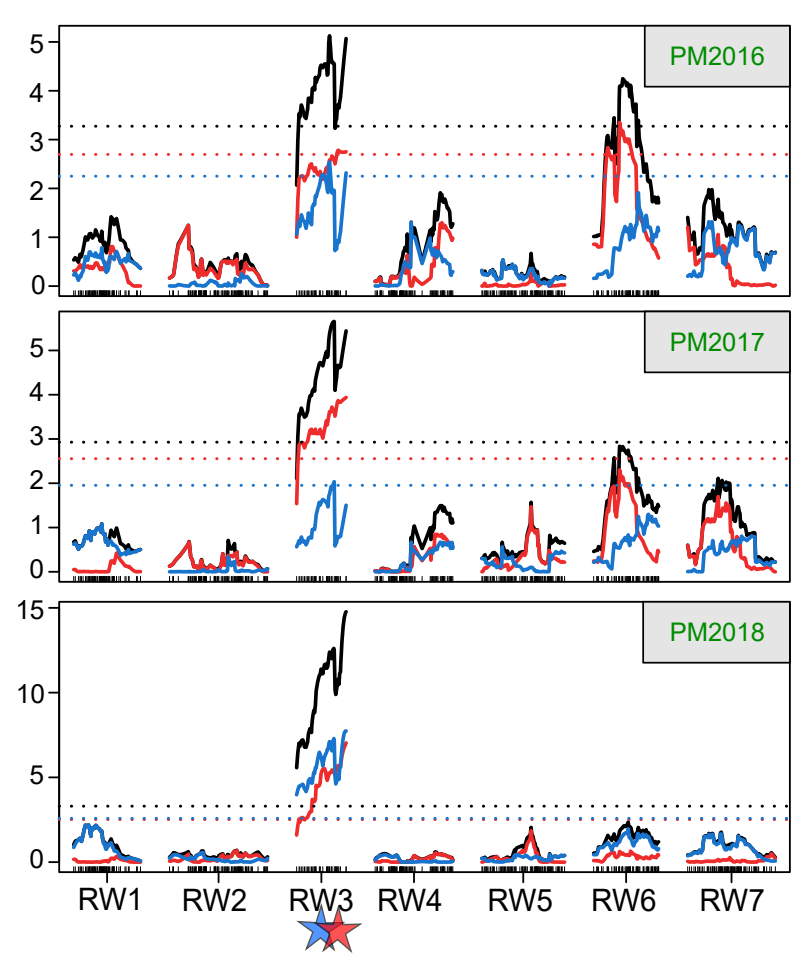

Figure 3 
a.

OB3

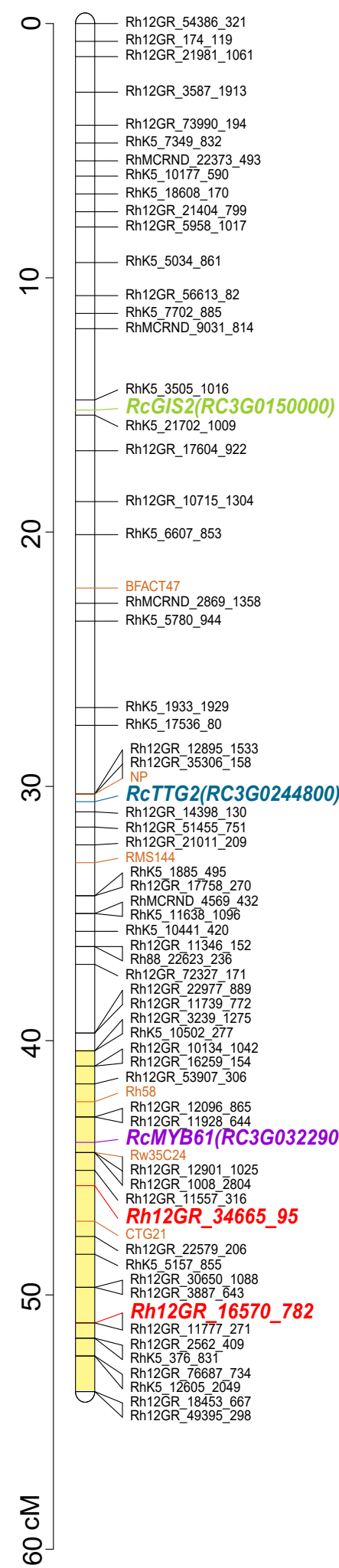

OB4

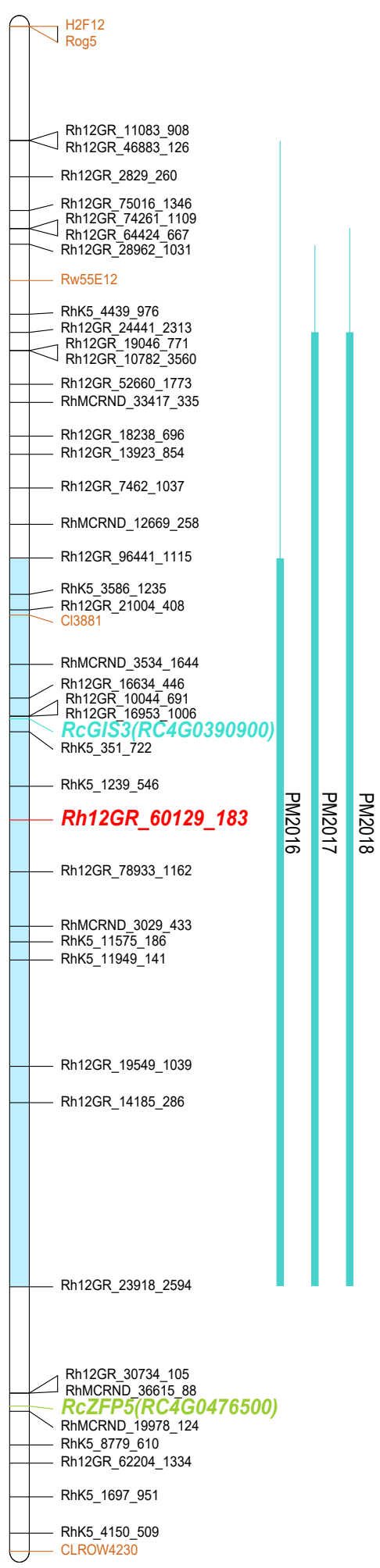


b.

RW1

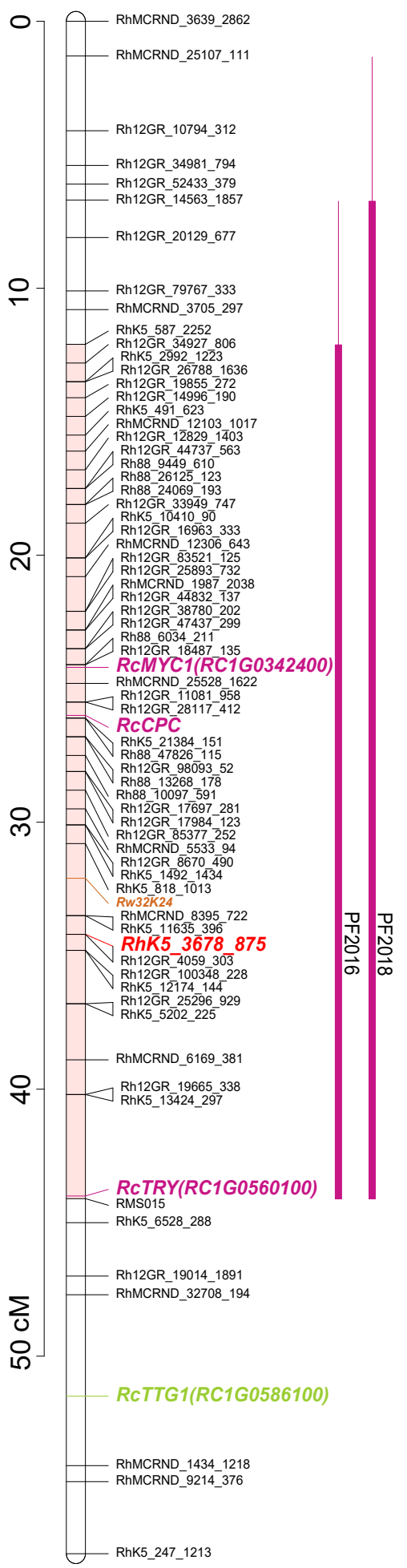

RW3

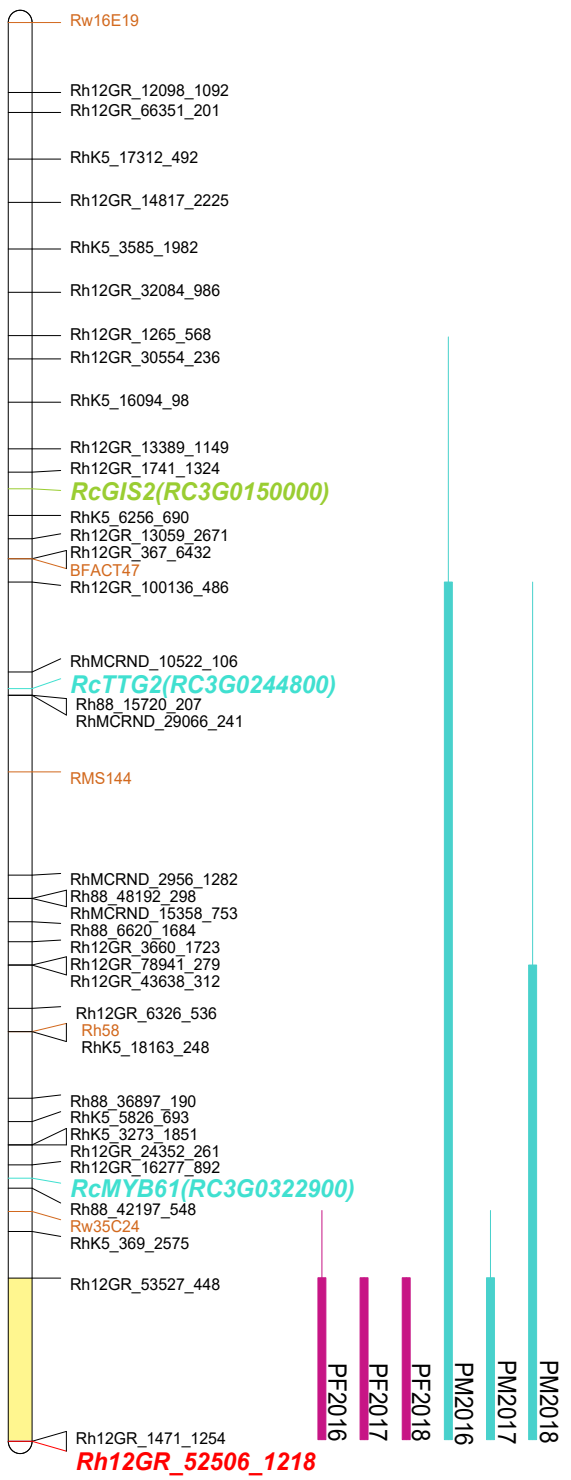

RW6

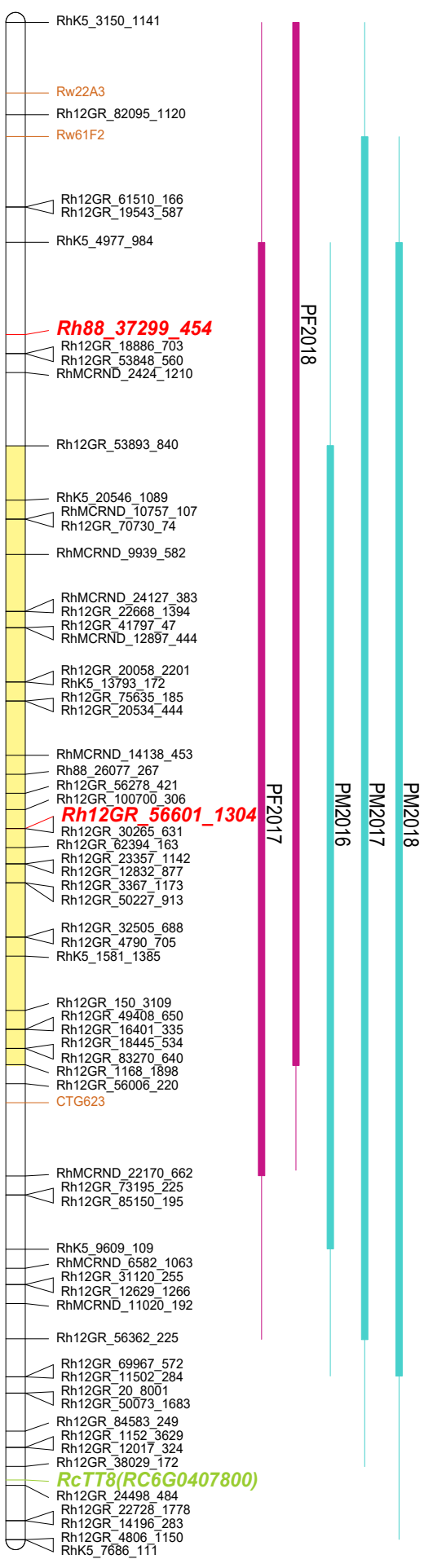

Figure 4 

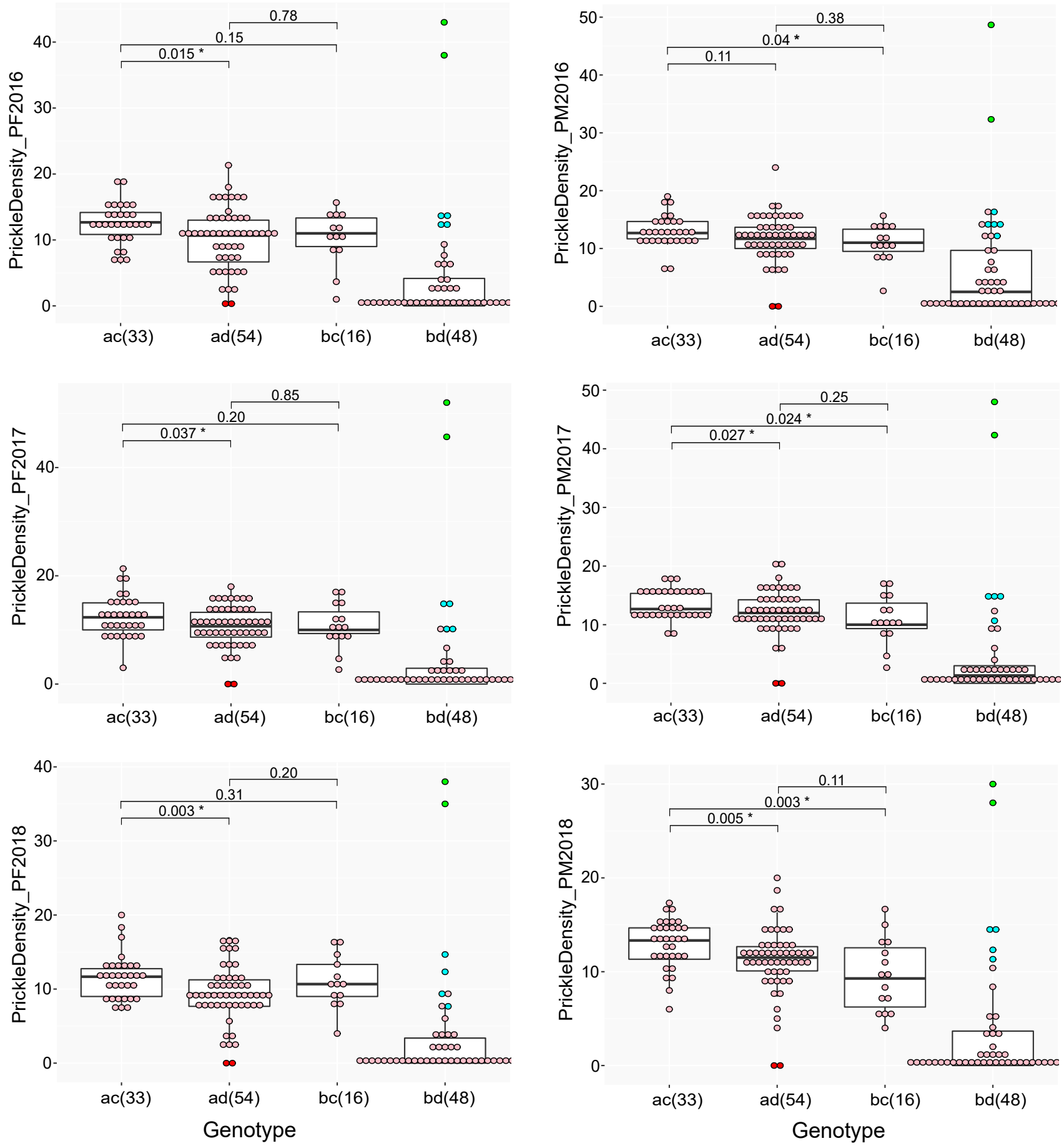

Figure 5 
a.

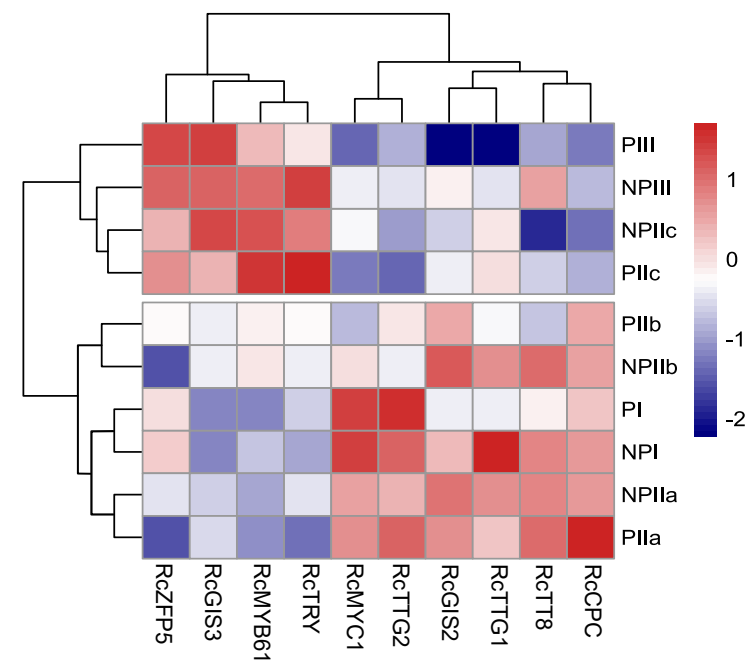

b.
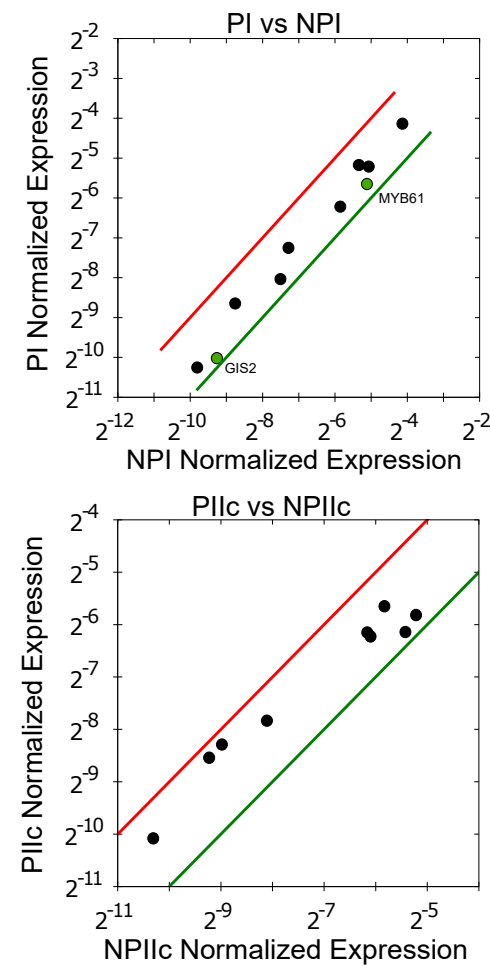

Plla vs NPIla
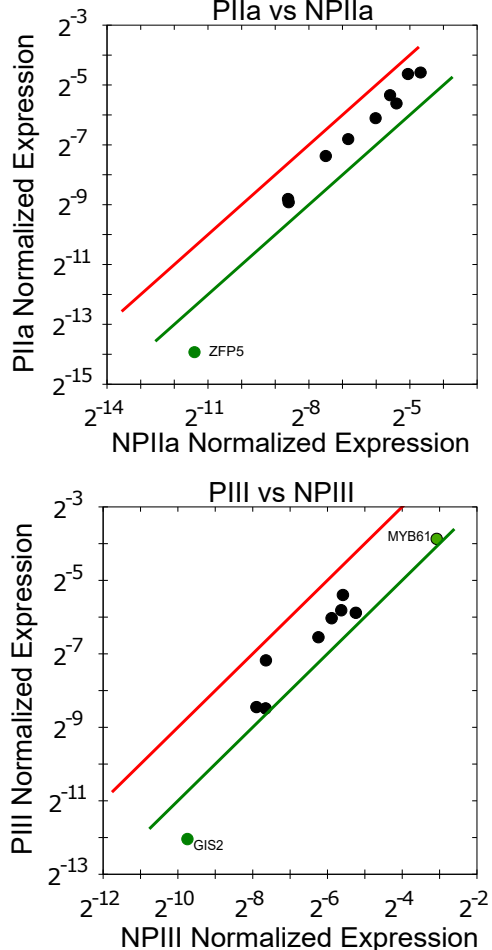

Pllb vs NPIlb

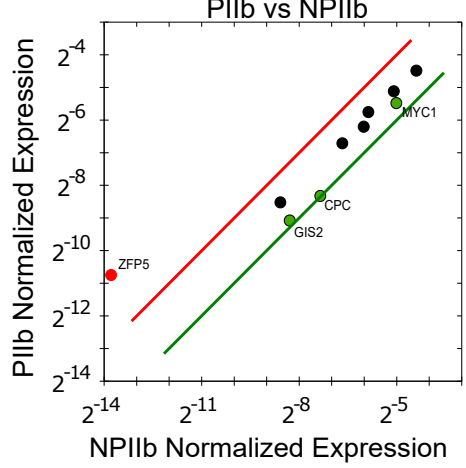

C.

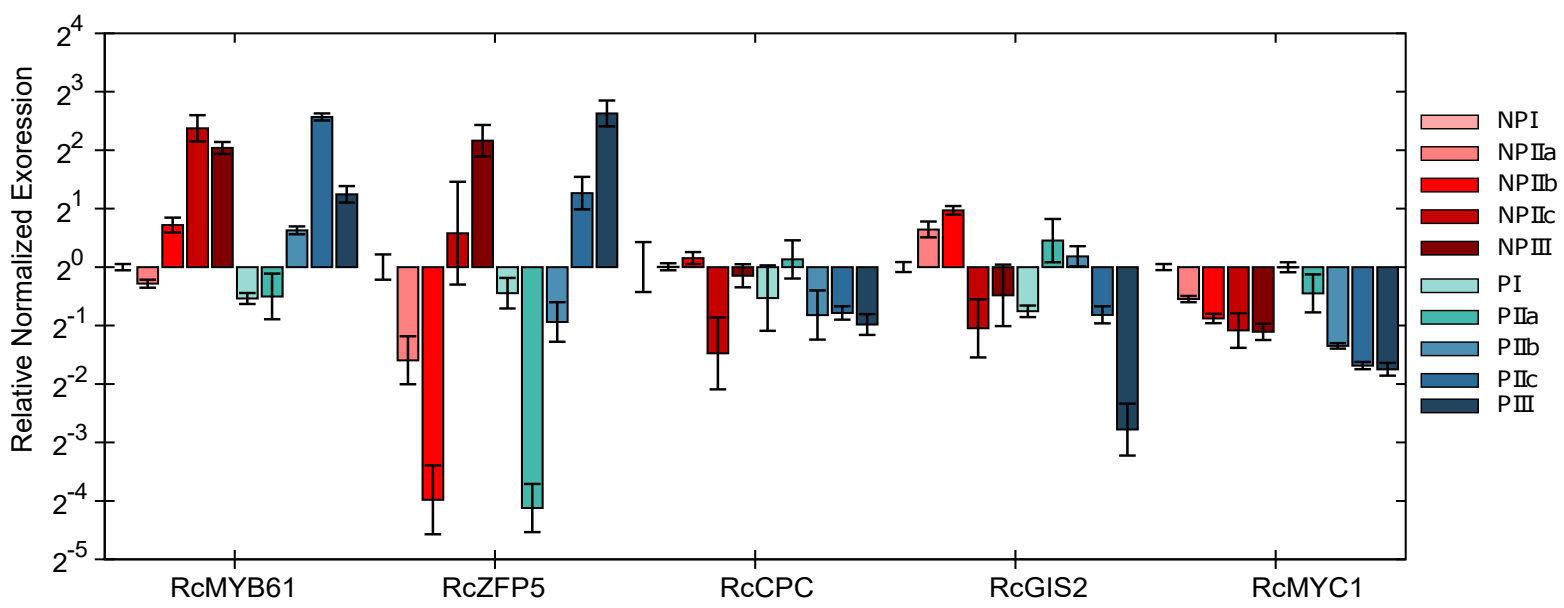

Figure 6 
Table 1 Mean, median and range values for prickle number on 4 internodes, phenotypic variance components and the trait heritability

\begin{tabular}{|c|c|c|c|c|c|c|c|c|c|c|c|c|c|c|c|}
\hline \multirow[b]{2}{*}{ Trait } & \multirow[b]{2}{*}{ Year } & \multirow{2}{*}{$\begin{array}{l}\text { OB } \\
\text { Mean } \pm \text { SD }\end{array}$} & \multirow{2}{*}{$\begin{array}{l}\text { RW } \\
\text { Mean } \pm \text { SD }\end{array}$} & \multicolumn{5}{|l|}{ F1 } & \multicolumn{4}{|c|}{ Kruskal-Wallis test (p-value) } & \multicolumn{3}{|c|}{ Variance com } \\
\hline & & & & range & $1 \mathrm{st} \mathrm{Qu}$ & Mean & median & 3rd Qu & Genotype & $\begin{array}{l}\text { Replicate } \\
\text { shoots }\end{array}$ & Year & Stem type & $\mathrm{SE}_{\mathrm{G}}$ & $\sigma_{\mathrm{GY}}^{2}$ & $\mathrm{SE}_{\mathrm{GY}}$ \\
\hline \multirow[t]{3}{*}{$\mathrm{PF}$} & 2016 & $11.3 \pm 1.3$ & $8.9 \pm 0.8$ & $0-43$ & 2.4 & 8.5 & 9.8 & 12.7 & & & & \multirow{6}{*}{ 4.93E- $08^{* * *}$} & \multirow{6}{*}{41.41} & \multirow{6}{*}{1.50} & \multirow{6}{*}{0.26} \\
\hline & 2017 & $11.6 \pm 1.1$ & $8.9 \pm 0.9$ & $0-52$ & 2.7 & 9.0 & 9.7 & 13.0 & $<2.20 \mathrm{E}-16^{* * *}$ & $0.96^{\mathrm{N}}$ & $0.06^{* *}$ & & & & \\
\hline & 2018 & $10.6 \pm 1.0$ & $8.4 \pm 0.5$ & $0-38$ & 2.7 & 7.9 & 9.0 & 11.3 & & & & & & & \\
\hline \multirow[t]{3}{*}{ PM } & 2016 & $11.9 \pm 1.6$ & $9.3 \pm 1.2$ & $0-48$ & 6.7 & 10.2 & 11.7 & 13.3 & \multirow{3}{*}{$<2.20 \mathrm{E}-16^{* * *}$} & \multirow{3}{*}{$0.81^{\mathrm{N}}$} & \multirow{3}{*}{$0.04^{* * *}$} & & & & \\
\hline & 2017 & $11.8 \pm 1.4$ & $9.2 \pm 1.1$ & $0-47$ & 3.0 & 10.2 & 11.3 & 14.0 & & & & & & & \\
\hline & 2018 & $11.7 \pm 1.6$ & $9.1 \pm 1.1$ & $0-30$ & 3.5 & 8.8 & 10.8 & 13.0 & & & & & & & \\
\hline
\end{tabular}

PF: prickles on the floral stem

PM: prickles on the main stem

1st Qu: First quartile(Q1) means 25\% observations are below this quantity (approx)

3rd Qu:Third quartile(Q3) means 75\% observations are below this quantity (approx)

$\sigma^{2}{ }_{G}$ :Variance components of genotype, genotype $\mathrm{x}$ year interaction $\left(\sigma_{\mathrm{GY}}^{2}\right)$, genotype $\mathrm{x}$ stem interaction $\left(\sigma_{\mathrm{GS}}^{2}\right)$, and the residual error $\left(\sigma_{\mathrm{E}}^{2}\right)$

SE: the standard error

$h^{2}$ : Narrow sense heritability 
jonent in $\sigma^{2}$

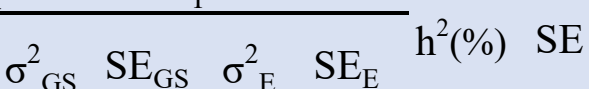

$\begin{array}{llllll}1.27 & 0.27 & 9.13 & 0.29 & 96.66 & 0.0048\end{array}$ 


\begin{tabular}{|c|c|c|c|c|c|c|c|c|c|c|c|}
\hline \multirow{2}{*}{ QTL } & \multirow{2}{*}{ Phenotyping } & \multirow{2}{*}{$\mathrm{PT}^{\mathrm{a}}$} & \multicolumn{5}{|c|}{ QTL Characteristics } & \multicolumn{2}{|c|}{0.95 bayes interval } & \multicolumn{2}{|c|}{0.99 bayes interval } \\
\hline & & & LOD & LG@positon ${ }^{\mathrm{b}}$ & $\mathrm{r}(\%)^{\mathrm{c}}$ & $\mathrm{MM}^{\mathrm{d}}$ & $\mathrm{bp}^{\mathrm{e}}$ & $\mathrm{cM}^{\mathrm{f}}$ & $\mathrm{bp}$ & $\mathrm{cM}$ & bp \\
\hline \multirow[t]{6}{*}{$1 a$} & PF2016 & 2.45 & 5.03 & OB3@51.1 & 11.74 & Rh12GR_16570_782 & 44459262 & $40.38-53.75$ & $36517224-46440369$ & $27.59-53.75$ & $27934327-46440369$ \\
\hline & PF2017 & 2.42 & 4.33 & OB3@51.1 & 6.92 & Rh12GR_16570_782 & 44459262 & $30.31-53.75$ & 33612066 - 46440369 & $20.14-53.75$ & 24888779 - 46440369 \\
\hline & PF2018 & 2.43 & 6.22 & OB3@51.1 & 14.84 & Rh12GR_16570_782 & 44459262 & $39.71-53.75$ & $36517224-46440369$ & $32.98-53.75$ & 33612066 - 46440369 \\
\hline & PM2016 & 2.31 & 2.31 & OB3@51.1 & 7.29 & Rh12GR_16570_782 & 44459262 & $27.59-53.75$ & $27934327-46440369$ & $15.43-53.75$ & $23585838-46440369$ \\
\hline & PM2017 & 2.49 & 3.58 & OB3@51.1 & 6.65 & Rh12GR_16570_782 & 44459262 & $20.14-53.75$ & $24888779-46474274$ & $18.8-53.75$ & $24000000-46440369$ \\
\hline & PM2018 & 2.51 & 4.48 & OB3@45.7 & 11.78 & Rh12GR_34665_95 & 41401120 & $36.99-53.75$ & $35014990-46440369$ & $20.14-53.75$ & $24888779-46440369$ \\
\hline \multirow[t]{6}{*}{$1 b$} & PF2016 & 2.42 & 8 & RW3@42.6 & 20.05 & Rh12GR_52506_1218 & 42317122 & $37.69-42.55$ & $41648024-42317122$ & $35.67-42.55$ & 40854291 - 42317122 \\
\hline & PF2017 & 2.38 & 8.31 & RW3@42.6 & 12.94 & Rh12GR_52506_1218 & 42317122 & $37.69-42.55$ & $024-423$ & $37.69-42.55$ & $24-423$ \\
\hline & PF2018 & 2.36 & 8.03 & RW3@42.6 & 21.45 & Rh12GR_52506_1218 & 42317122 & $37.69-42.55$ & $024-42317122$ & $37.69-42.55$ & $41648024-42317122$ \\
\hline & PM2016 & 2.51 & 5.88 & RW3@42.6 & 12.76 & Rh12GR_52506_1218 & 42317122 & $16.8-42.55$ & $32557591-42317122$ & $9.44-42.55$ & $16767733-42317122$ \\
\hline & PM2017 & 2.41 & 9.56 & RW3@42.6 & 12.12 & Rh12GR_52506_1218 & 42317122 & $37.69-42.55$ & 41648024 - 42317122 & $35.67-42.55$ & 40854291 - 42317122 \\
\hline & PM2018 & 2.5 & 11.5 & RW3@42.6 & 37.40 & Rh12GR_52506_1218 & 42317122 & $28.3-42.55$ & $925-42$ & $16.8-42.55$ & $591-42-2-2$ \\
\hline \multirow[t]{3}{*}{2} & PM2016 & 2.31 & 2.89 & OB4@30.6 & 11.64 & Rh12GR_60129_183 & 52239028 & $20.53-48.59$ & $46189407-56107784$ & $5.77-48.59$ & 95 - 56107784 \\
\hline & PM2017 & 2.49 & 3.15 & OB4@30.6 & 13.18 & Rh12GR_60129_183 & 52239028 & $11.81-48.59$ & $36731337-56107784$ & $4.43-48.59$ & 30431277 - 56107784 \\
\hline & PM2018 & 2.51 & 3.3 & OB4@30.6 & 10.35 & Rh12GR_60129_183 & 52239028 & $11.81-48.59$ & 36731337 - 56107784 & $7.78-48.59$ & $538-56107784$ \\
\hline \multirow[t]{5}{*}{3} & PF2017 & 2.38 & 2.8 & RW6@29.7 & 6.73 & Rh12GR_56601_1304 & 31814891 & $8.11-42.49$ & 4339433 - 44264630 & $0-48.52$ & 1518964 - 48810479 \\
\hline & PF2018 & 2.36 & 2.81 & RW6@11.5 & 6.67 & Rh88_37299_454 & 5410244 & $6.74-44.11$ & 7764439 - 62612495 & $1.34-54.05$ & $1461254-64122872$ \\
\hline & PM2016 & 2.51 & 4.16 & RW6@29.7 & 8.45 & Rh12GR_56601_1304 & 31814891 & $0-38.43$ & 1518964 - 48896977 & $0-42.49$ & $1518964-44264630$ \\
\hline & PM2017 & 2.41 & 2.7 & RW6@29.7 & 7.07 & Rh12GR_56601_1304 & 31814891 & $15.59-45.19$ & 8578645 - 45439915 & $8.11-49.9$ & $4339433-41715319$ \\
\hline & PM2018 & 2.5 & 2.58 & RW6@29.7 & 5.28 & Rh12GR_56601_1304 & 31814891 & $4.21-48.53$ & 3340353 - 48180089 & $0-53.21$ & 1518964 - 52689670 \\
\hline \multirow[t]{2}{*}{4} & PF2016 & 2.42 & 3.08 & RW1@34.2 & 6.52 & RhK5_3678_875 & 59006755 & $12.78-44.11$ & $20231658-62553371$ & $6.74-54.05$ & 7764439 - 64122872 \\
\hline & PF2018 & 2.36 & 3.04 & RW1@34.2 & 6.99 & RhK5_3678_875 & 59006755 & $6.74-44.11$ & $7764439-62553371$ & $1.34-54.05$ & $3670420-64122872$ \\
\hline
\end{tabular}

${ }^{\mathrm{a}} \mathrm{PT}$ genome-wild LOD significance threshold was defined by a permutation test. ${ }^{\mathrm{b}}$ LG@positon chromosomal linkage group, using the separate map (OB and RW) numbering of (Hibrand-Saint Oyant et al., 2018) @ peak location in cM. ${ }^{\mathrm{c}}$ r(\%) Percentage of explanation. ${ }^{\mathrm{d}}$ Closest molecular marker (MM) associated. ${ }^{\mathrm{e}}$ location in base pair (bp) on the Rosa chinesis Genome v1.0 (Hibrand-Saint Oyant et al., 2018). ${ }^{\mathrm{f}}$ centiMorgan position of QTL peak. 

. NGP

(OW9137)

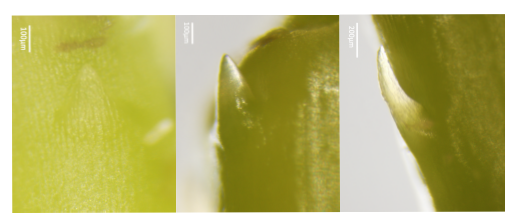

PI

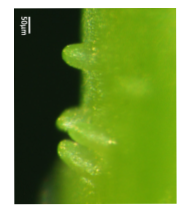

PI

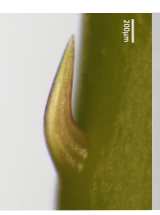

PIIa

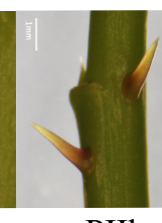

PIIb

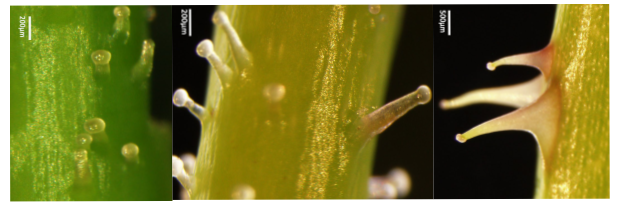

PIIc

PIIa

PIIb

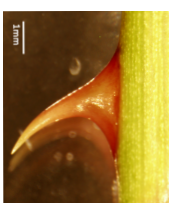

PIII

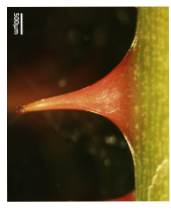

PIII

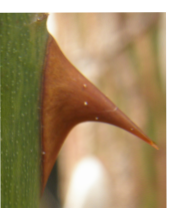

PIV

b. GP

(OW9106)

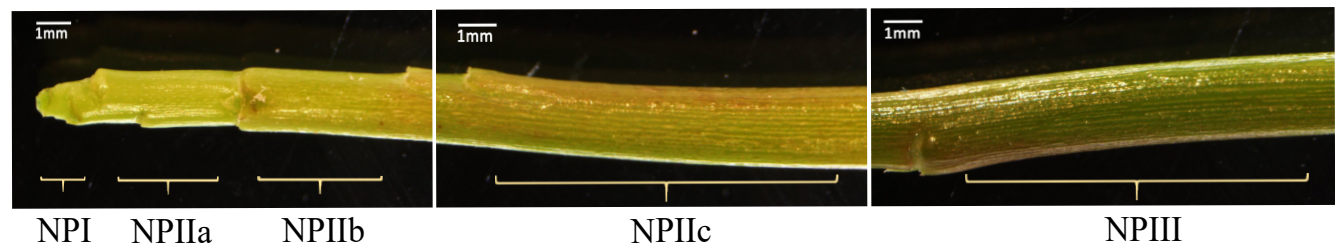

NPIIc

NPIII (OW9068)

Supplementary Figure 1 

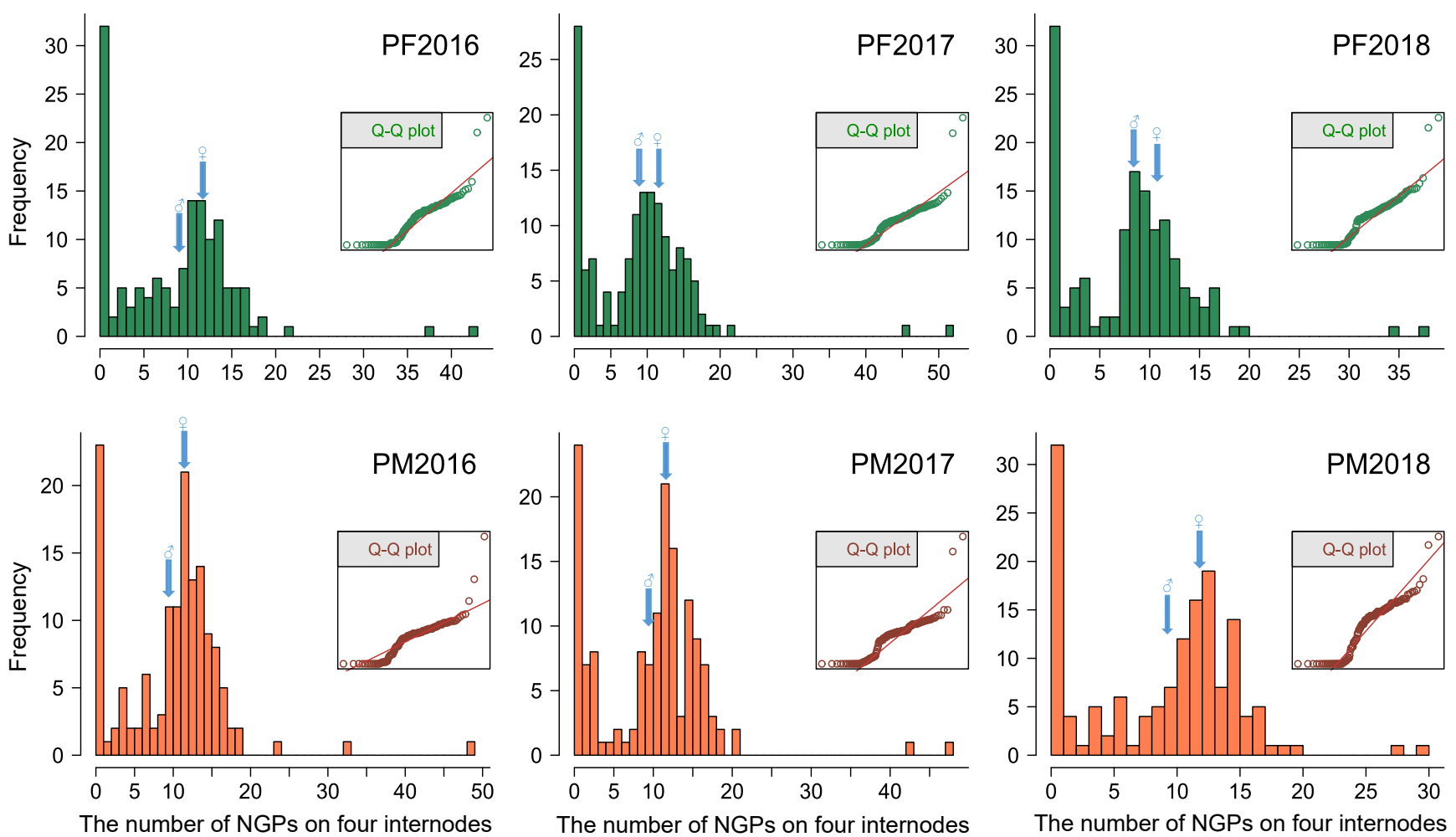

Supplementary Figure 2 


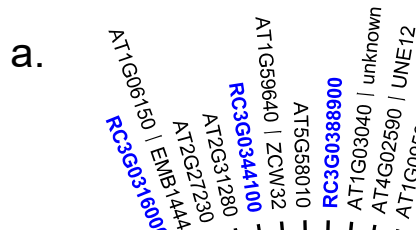

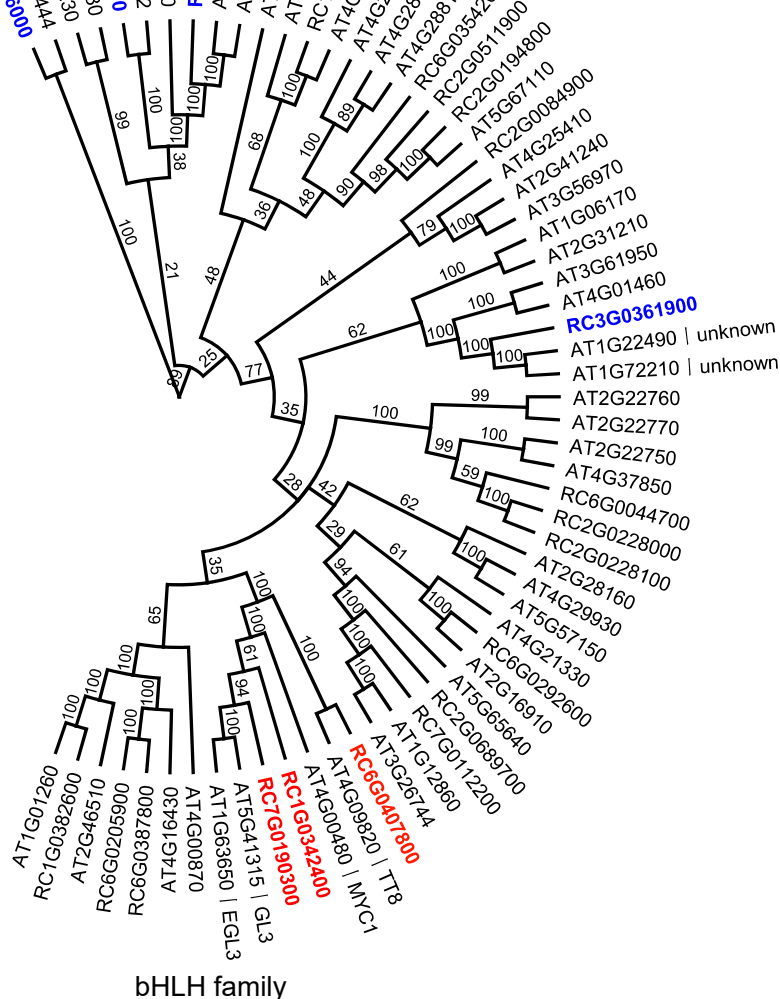

bHLH family

c.

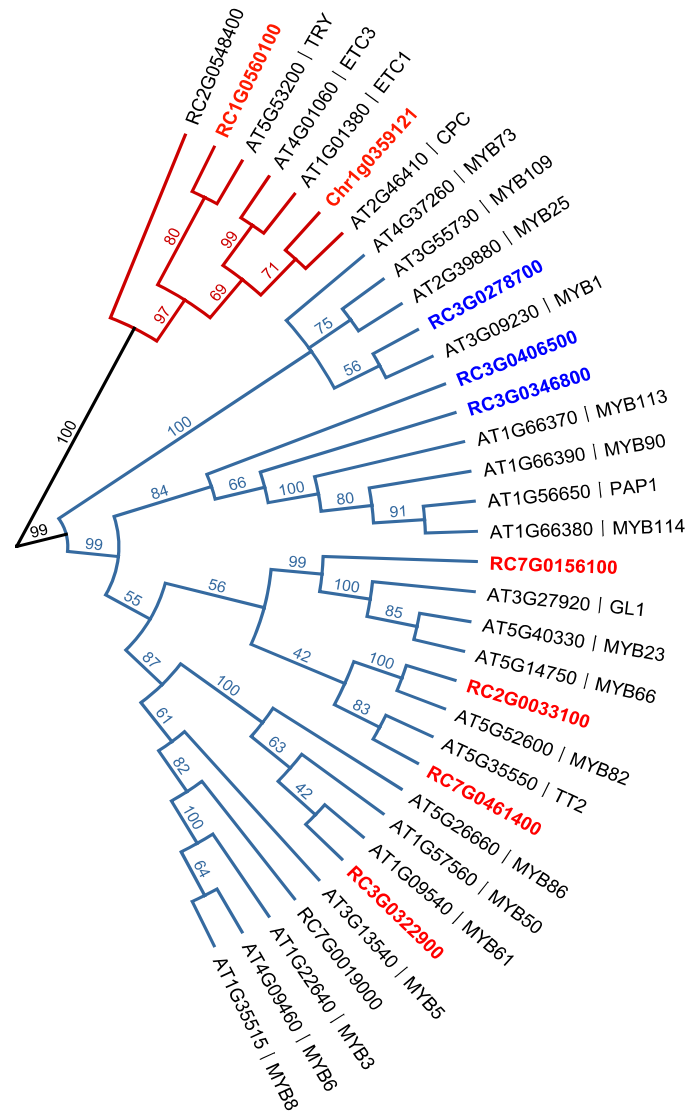

MYB family

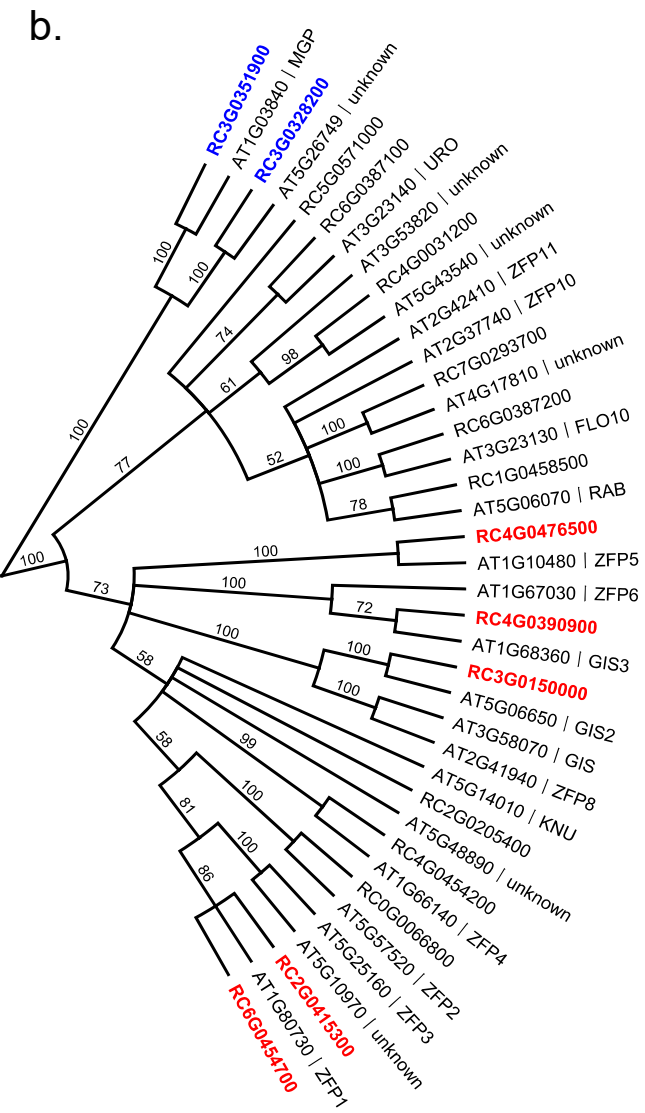

$\mathrm{C} 2 \mathrm{H} 2$ family

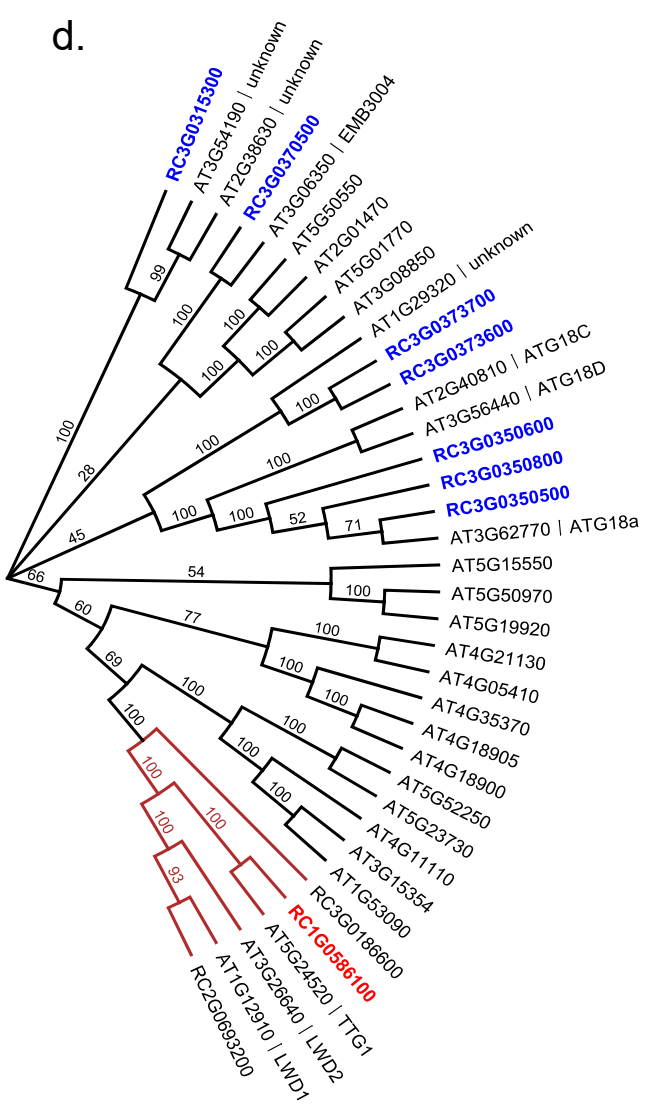

WD40 family 
Supplementary Table 1. Primer sequences of candidate genes for qPCR

\begin{tabular}{ll}
\hline Primer name & sequence of primers \\
\hline RcMYC1-1-F & 5' CCACCCTCAATGATGTTCTC 3' \\
RcMYC1-1-R & 5' TTCTGGCGTCTCAACACTTAC 3' \\
RcTT8-1-F & 5' AGAGAGCGATGGATTGTTGG 3' \\
RcTT8-1-R & 5' GCCCTCTTCACTTCTGTAATGG 3' \\
RcGIS2-1-F & 5' CTGGTGACTCCGTTGTTCG 3' \\
RcGIS2-1-R & 5' TCCCTAAGATGGATGGATTGA 3' \\
RcGIS3-1-F & 5' GGCCATCGTTGAGTAGGTTC 3' \\
RcGIS3-1-R & 5' GGAGTCAGAGGCTGAGTTGC 3' \\
RcTRY-1-F & 5' GGAAAGCAGAAGAAATAGAGAGG 3' \\
RcTRY-1-R & 5' CTACTACTGACAAGGAAAACCAATG 3' \\
RcTTG1-1-F & 5' TCCAATGTCAATGTACTCGGC 3' \\
RcTTG1-1-R & 5' CCTCCTCAAACCTTCAACAGC 3' \\
RcTTG2-1-F & 5' CCTCAAACCCAGGAGCATC 3' \\
RcTTG2-1-R & 5' CAACAGCTTGATCCCTGAGAG 3' \\
RcCPC-F & 5' GACATTGTGAGGTGTTTGCTGAG 3' \\
RcCPC-R & 5' AATCCGCTGAAAGTTCGACG 3' \\
RcMYB61-F & 5' GGATCTTCAGAGACTCGCTGTAGC 3' \\
RcMYB61-R & 5' CAAGCCCTCCTCTCACATTCAT 3' \\
RcZFP5-F & 5' CAGGAGAAAGCAGACCAGTGAT 3' \\
RcZFP5-R & 5' GGCAAGCCAATCCCTAACTG 3' \\
\hline
\end{tabular}


Supplementary Table 2. Summary of QTLs for NGP with two-part QTL model in OW progeny

\begin{tabular}{|c|c|c|c|c|c|c|}
\hline \multirow{2}{*}{ Trait } & \multirow{2}{*}{ Phenotyping } & \multirow{2}{*}{$\mathrm{PT}^{\mathrm{a}}$} & \multicolumn{4}{|c|}{ QTL Characteristics } \\
\hline & & & LG@positon ${ }^{\text {b }}$ & $\mathrm{MM}^{\mathrm{c}}$ & $b d^{d}$ & $r(\%)^{e}$ \\
\hline \multirow{14}{*}{$\operatorname{Binary}(p)$} & PF2016 & 2.57 & OB3@44.4 & Rw35C24 & $40,215,502$ & 15.93 \\
\hline & PF2017 & 2.53 & OB3@44.4 & Rw35C24 & $40,215,502$ & 15.18 \\
\hline & PF2018 & 2.6 & OB3@44.4 & Rw35C24 & $40,215,502$ & 16.12 \\
\hline & PM2016 & 2.47 & OB3@44.4 & Rw35C24 & $40,215,502$ & 14.76 \\
\hline & PM2017 & 2.58 & OB3@44.4 & Rw35C24 & $40,215,502$ & 13.38 \\
\hline & PM2018 & 2.51 & OB3@44.4 & Rw35C24 & $40,215,502$ & 16.72 \\
\hline & PF2016 & 2.67 & RW3@42.6 & Rh12GR_52506_1218 & $42,317,122$ & 29.31 \\
\hline & PF2017 & 2.59 & RW3@42.6 & Rh12GR_52506_1218 & $42,317,122$ & 30.33 \\
\hline & PF2018 & 2.57 & RW3@42.6 & Rh12GR_52506_1218 & $42,317,122$ & 28.72 \\
\hline & PM2016 & 2.54 & RW3@42.6 & Rh12GR_52506_1218 & $42,317,122$ & 20.69 \\
\hline & PM2017 & 2.56 & RW3@42.6 & Rh12GR_52506_1218 & $42,317,122$ & 26.84 \\
\hline & PM2018 & 2.59 & RW3@42.6 & Rh12GR_52506_1218 & $42,317,122$ & 33.21 \\
\hline & PF2016 & 2.67 & RW2@16.2 & CTG356 & $1,674,220$ & 1.80 \\
\hline & PM2016 & 2.47 & RW6@22.3 & RhMCRND_12897_444 & $17,698,816$ & 2.70 \\
\hline \multirow{9}{*}{ Quntitative $(\mu)$} & PF2016 & 2.42 & OB4@30.6 & Rh12GR_60129_183 & $52,239,028$ & 9.02 \\
\hline & PM2016 & 2.36 & OB4@30.6 & Rh12GR_60129_183 & $52,239,028$ & 9.26 \\
\hline & PM2017 & 1.92 & OB4@30.6 & Rh12GR_60129_183 & $52,239,028$ & 9.88 \\
\hline & PM2018 & 2.8 & OB1@67.7 & Rh12GR_62822_144 & 7388536 and $7,633,108$ & 6.66 \\
\hline & PF2016 & 2.39 & RW3@42.6 & Rh12GR_52506_1218 & $42,317,122$ & 20.98 \\
\hline & PM2016 & 2.26 & RW3@28.3 & Rh12GR_78941_279 & $36,727,828$ & 14.23 \\
\hline & PM2017 & 1.88 & RW3@32.3 & Rh88_36897_190 & $38,554,327$ & 12.61 \\
\hline & PM2018 & 2.52 & RW3@42.6 & Rh12GR_52506_1218 & $42,317,122$ & 38.64 \\
\hline & PF2018 & 2.57 & RW1@24.1 & Rh88_6034_211 & $45,638,457$ & 7.80 \\
\hline
\end{tabular}

${ }^{\mathrm{a}}$ PT genome-wild LOD significance threshold was defined by a permutation test. ${ }^{\mathrm{b}}$ LG@positonchromosomal linkage group, using the separate map (OB and RW) numbering of (Hibrand-Saint Oyant et al., 2018)@ peak location in $\mathrm{cM}^{\mathrm{c}}{ }^{\mathrm{C}}$ Closest molecular marker (MM) associated. ${ }^{\mathrm{d}}$ location in base pair (bp) on the Rosa chinesis Genome v1.0 (Hibrand-Saint Oyant et al., 2018). ${ }^{\mathrm{e}} \mathrm{r}(\%)$ Percentage of explanation. 


\begin{tabular}{|c|c|c|c|c|c|c|}
\hline Family & AT genes & Function description & Mutant vs WT & Rose gene name & Rose geneID & Genome location \\
\hline \multirow[t]{3}{*}{ R2R3MYB } & 3 AT3G27920/GL1 & Interacts with JAZ and DELLA proteins to regulate trichome initiation & No trichome & RcGL1 & RC7G0156100 & Chr07:11958961..11961286 (2.33 Kb) \\
\hline & AT5G52600/MYB82 & $\begin{array}{l}\text { MYB82 and GL1 can form homodimers and heterodimers at R2R3-MYB domains. At least one of } \\
\text { the two introns in MYB82 is essential to the protein's trichome developmental function }\end{array}$ & & RcMYB82 & RC2G0033100 & Chr02:2470719..2472719 (2 Kb) \\
\hline & AT1G09540/MYB61 & Affects trichome initiation, root development and stomatal aperture & Fewer trichome & RcMYB61 & RC3G0322900 & Chr03:39896892.. 39899077(2.18kb) \\
\hline \multirow[t]{2}{*}{ R3MYB } & $\mathrm{AT} 2 \mathrm{G} 46410 / \mathrm{CPC}$ & Positive regulator of hair-cell differentiation. Preferentially transcribed in hairless cells. & Increase density & $\mathrm{RcCPC}$ & Chrlg0359121 & Ch01: $47708266 . .47710558 \mathrm{bp}(2.32 \mathrm{~kb})$ \\
\hline & AT5G53200/TRY & Involved in trichome branching & cluster phenotype & RcTRY & RC1G0560100 & Chr01:62070383..62072848(2.47 Kb) \\
\hline \multirow[t]{3}{*}{ bHLH } & AT5G41315/GL3 & $\begin{array}{l}\text { Encodes a basic helix loop helix domain protein that interacts with GL1 in trichome development. } \\
\text { GL3 interacts with JAZ and DELLA proteins to regulate trichome initiation. }\end{array}$ & Fewer trichome & RcGL3 & RC7G0190300 & Chr07:15536877..15543259 (6.38 Kb) \\
\hline & AT4G09820/TT8 & $\begin{array}{l}\text { TT8 is a regulation factor that acts in a concerted action with TT1, PAP1 and TTG1 on the } \\
\text { regulation of flavonoid pathways, Also important for marginal trichome development. }\end{array}$ & Fewer trichome & RcTT8 & RC6G0407800 & Chr06:52002793..52009528 (6.74 Kb) \\
\hline & AT4G00480/MYC1 & $\begin{array}{l}\text { MYC-related protein with a basic helix-loop-helix motif at the } \mathrm{C} \text {-terminus and a region similar to } \\
\text { the maize } \mathrm{B} / \mathrm{R} \text { family at the } \mathrm{N} \text {-terminus }\end{array}$ & Fewer trichome & RcMYC1 & RC1G0342400 & Chr01:44468298..44473643 (5.35 Kb) \\
\hline WD40 & AT5G24520/TTG1 & Involved in trichome and root hair development. Controls epidermal cell fate specification. & No trichome & RcTTG1 & RC1G0586100 & Chr01:63982095..63985616 (3.52 Kb) \\
\hline WRKY & AT2G37260/TTG2 & Trichome development & $\begin{array}{l}\text { Trichome clusters } \\
\text { and a reduced } \\
\text { trichome number }\end{array}$ & RcTTG2 & RC3G0244800 & Chr03:33397852..33403551 (5.7 Kb) \\
\hline \multirow[t]{5}{*}{$\mathrm{C} 2 \mathrm{H} 2$} & AT1G10480/ZFP5 & $\begin{array}{l}\text { Acts downstream of ZFP6 in regulating trichome development by integrating GA and cytokinin } \\
\text { signaling. }\end{array}$ & & RcZFP5 & RC4G0476500 & Chr04:57125905..57127513 (1.61 Kb) \\
\hline & AT1G68360/GIS3 & $\begin{array}{l}\text { GIS3 is involved in trichome initiation and development downstream of GA and cytokinin } \\
\text { signaling. }\end{array}$ & & RcGIS3 & RC4G0390900 & Chr04:50315805..50317009 (1.21 Kb) \\
\hline & AT1G80730/ZFP1 & Expressed at high levels in the shoot apex, including the apical meristem, developing leaves and & & RcZFP1-like1 & RC2G0415300 & Chr02:47908413..47909551 (1.14 Kb) \\
\hline & & the developing vascular system & & RcZFP1-like2 & RC6G0454700 & Chr06:55856328..55858302 (1.98 Kb) \\
\hline & AT5G06650/GIS2 & Regulates trichome formation on inflorescence stems; is also influenced by cytokinins & & RcGIS2 & RC3G0150000 & Chr03:23331984..23333173 (1.19 Kb) \\
\hline \multirow{3}{*}{\multicolumn{2}{|c|}{ HD-ZIP IV AT1G79840/GL2 }} & A homeodomain protein affects epidermal cell identity including trichomes, root hairs and seed & & RcGL2 & RC2G0467100 & Chr02:54366345..54368366 (2.02 Kb) \\
\hline & & coat & & & RC2G0467200 & Chr02:54367536..54371324 (3.79 Kb) \\
\hline & & & & & Chr2g0138951 & Che02:54366345..54371324(5.81 Kb) \\
\hline
\end{tabular}


Supplementary Table 4 Prickle number on four internodes of two types of

stems for three years in OW progeny

\begin{tabular}{|c|c|c|c|c|c|c|}
\hline Indiciduals & PF2016 & PF2017 & PF2018 & PM2016 & PM2017 & PM2018 \\
\hline Ow9001 & 0.67 & 5 & 2.67 & 10 & 12.67 & 10.33 \\
\hline Ow9003 & 0 & 0 & 0 & 14 & 12.33 & 8.33 \\
\hline Ow9004 & 2 & 3 & 0.33 & 3 & 3 & 0 \\
\hline Ow9005 & 10.67 & 12 & 11.67 & 10.67 & 12.33 & 11 \\
\hline Ow9006 & 3.67 & 4 & 9 & 3.67 & 4 & 0 \\
\hline Ow9007 & 3.67 & 4.67 & 8.33 & 10 & 4.67 & 5.67 \\
\hline Ow9008 & 6 & 0.67 & 0 & 6 & 2.67 & 1.33 \\
\hline Ow9009 & 7 & 4.33 & 2 & 7 & 5.33 & 12.33 \\
\hline Ow9010 & 11.67 & 11 & 7.67 & 11.67 & 15.67 & 12.67 \\
\hline Ow9011 & 11 & 11.67 & 9 & 11 & 11.67 & 11.67 \\
\hline Ow9012 & 11.67 & 14.67 & 11.67 & 15 & 17 & 14.33 \\
\hline Ow9013 & 1 & 2.67 & 4 & 2.67 & 2.67 & 4 \\
\hline Ow9014 & 2.33 & 10 & 0.67 & 9.67 & 10 & 2 \\
\hline Ow9016 & NA & NA & NA & 8.33 & NA & NA \\
\hline Ow9017 & 15.67 & 17 & 14.33 & 15.67 & 18.33 & 14.67 \\
\hline Ow9018 & 9.67 & 8.67 & 11.33 & 9.67 & 8.67 & 10 \\
\hline Ow9019 & 0 & 0 & 0 & 0 & 0 & 0 \\
\hline Ow9021 & 13.67 & 15.33 & 14.67 & 13.67 & 15.33 & 14.33 \\
\hline Ow9022 & 9.67 & 10 & 7.67 & 11.33 & 9.67 & 9.33 \\
\hline Ow9023 & 15.33 & 15.67 & 13.67 & 15.33 & 15.67 & 14.33 \\
\hline Ow9024 & 16 & 13 & 11.33 & 16 & 16.67 & 16.33 \\
\hline Ow9025 & 14 & 13 & 11.67 & 14 & 13 & 13.67 \\
\hline Ow9027 & 13 & 8.67 & 8.33 & 13 & 8.67 & 9 \\
\hline Ow9029 & 10 & 10 & 7.67 & 10 & 10 & 8.33 \\
\hline Ow9030 & 10.67 & 10.67 & 11.67 & 12 & 11 & 11.33 \\
\hline Ow9031 & 12.33 & 12.33 & 8.33 & 12.33 & 12.33 & 15.33 \\
\hline Ow9032 & 9.33 & 6.67 & 3.33 & 14.33 & 2 & 0.33 \\
\hline Ow9033 & 12.33 & 11 & 9 & 12.33 & 12 & 13.33 \\
\hline Ow9034 & 15.67 & 17.33 & 13.33 & 15.67 & 17.33 & 15 \\
\hline Ow9035 & 14 & 15 & 16.67 & 14 & 15 & 5 \\
\hline Ow9036 & 0 & 0 & 0 & 0 & 0 & 0 \\
\hline Ow9037 & 0 & 0.67 & 2 & 0.33 & 0.67 & 1 \\
\hline Ow9038 & 0 & 0 & 0 & 7.67 & 2.33 & 5.33 \\
\hline Ow9039 & 10.33 & 13 & 10.33 & 13.67 & 12 & 14.33 \\
\hline Ow9040 & 11.67 & 11.67 & 9 & 11.67 & 12 & 10.33 \\
\hline Ow9041 & 5.67 & 6.67 & 8.67 & 5.67 & 6.67 & 10.33 \\
\hline Ow9042 & 11.67 & 9.67 & 13 & 11.67 & 12.67 & 13.67 \\
\hline Ow9044 & 0.67 & 1 & 0.67 & 3.33 & 1 & 0 \\
\hline Ow9045 & 3.33 & 4.33 & 4.33 & 3.33 & 2.67 & 3.67 \\
\hline Ow9046 & 0 & 0.33 & 4 & 12.67 & 0.33 & 0.33 \\
\hline Ow9047 & 4.33 & 2 & 6 & 4.33 & 2 & 0 \\
\hline Ow9049 & 1 & 0 & 4 & 1 & 0 & 0 \\
\hline Ow9050 & 14 & 15.33 & 16 & 14 & 15.33 & 13.33 \\
\hline Ow9051 & 0.67 & 0.33 & 0 & 0.67 & 0.33 & 0.33 \\
\hline Ow9052 & 13.67 & 14.33 & 12.33 & 16.33 & 14.33 & 12.33 \\
\hline Ow9054 & 0 & 0 & 0 & 0 & 0 & 0 \\
\hline Ow9055 & 6.67 & 6.67 & 9.33 & 6.67 & 11 & 11.67 \\
\hline
\end{tabular}




\begin{tabular}{|c|c|c|c|c|c|c|}
\hline Ow9056 & NA & 0 & 0 & 0 & 0 & 0 \\
\hline Ow9057 & 0 & 0 & 0 & 0 & 0 & 0 \\
\hline Ow9058 & NA & 0 & 0 & 0 & 0 & 0 \\
\hline Ow9059 & 0.33 & 1.33 & 0.33 & 0.33 & 1.33 & 0.67 \\
\hline Ow9060 & 1 & 1.33 & 2.67 & 1 & 1.33 & 1 \\
\hline Ow9061 & 12.67 & 12 & 9.33 & 11.33 & 12 & 12.33 \\
\hline Ow9062 & 12.67 & 9.67 & 7.67 & 14.67 & 14.33 & 14.67 \\
\hline Ow9065 & 2 & 1.67 & 0 & 3.67 & 8.67 & 4 \\
\hline Ow9066 & 2.33 & 6.33 & 3.67 & 10.67 & 10 & 11 \\
\hline Ow9067 & 0 & 0 & 0 & 0 & 0 & 0 \\
\hline Ow9068 & 0 & 0 & 0 & 0 & 0 & 0 \\
\hline Ow9069 & 14.33 & 14.67 & 11 & 14.33 & 14.67 & 13 \\
\hline Ow9071 & 14 & 21.33 & 12.67 & 18.67 & 16 & 13.67 \\
\hline Ow9072 & 16.67 & 16.67 & 13 & 16.67 & 16.67 & 12.33 \\
\hline Ow9074 & 11.67 & 11 & 10.33 & 11.67 & 11 & 5.67 \\
\hline Ow9075 & 11.67 & 14 & 9.33 & 11.67 & 14 & 12.67 \\
\hline Ow9076 & 2.67 & 3 & 1.67 & 11.67 & 3 & 0 \\
\hline Ow9077 & 10.67 & 9.67 & 10.33 & 10.67 & 15 & 14.33 \\
\hline Ow9078 & 0.67 & 0 & 0 & 0.67 & 0 & 0 \\
\hline Ow9079 & 11.67 & 8.67 & 7.67 & 11.67 & 12 & 12 \\
\hline Ow9080 & 12.67 & 10.33 & 9.67 & 13.33 & 16.33 & 12.33 \\
\hline Ow9081 & 13 & 13 & 12.33 & 13 & 15 & 15.33 \\
\hline Ow9082 & 9.33 & 12 & 11.33 & 9.33 & 12 & 11.33 \\
\hline Ow9083 & 12 & 9 & 9 & 12 & 9 & 12 \\
\hline Ow9084 & 14.33 & 14 & 13.67 & 15.67 & 20.33 & 17 \\
\hline Ow9085 & 12 & 3 & 10 & 12 & 12 & 13 \\
\hline Ow9087 & 14.33 & 15 & 12.67 & 14.33 & 15.33 & 14.67 \\
\hline Ow9088 & 10.33 & 11.33 & 10.33 & 12.33 & 11.33 & 11 \\
\hline Ow9089 & 13.33 & 13.67 & 13 & 13.33 & 15 & 15.33 \\
\hline Ow9091 & 0.67 & 1 & 0.67 & 0.67 & 1 & 0 \\
\hline Ow9092 & 8 & 7.33 & 8.33 & 15.67 & 12 & 6 \\
\hline Ow9095 & 11 & 11.33 & 7.33 & 11 & 11.33 & 12.33 \\
\hline Ow9096 & 5.67 & 10.67 & 9.33 & 9.67 & 10.67 & 11 \\
\hline Ow9098 & 2.67 & 10.67 & 9.33 & 9.33 & 11 & 11.33 \\
\hline Ow9099 & 13.33 & 12 & 14.67 & 13.33 & 12.67 & 9.33 \\
\hline Ow9100 & 6.67 & 8 & 8.33 & 6.67 & 8 & 9.33 \\
\hline Ow9101 & 15 & 16 & 11.33 & 15 & 15 & 17.33 \\
\hline Ow9103 & 15 & 8.67 & 11 & 15 & 15 & 14.33 \\
\hline Ow9104 & 10.67 & 12.33 & 9 & 13 & 11.67 & 13 \\
\hline Ow9105 & 12.67 & 12 & 8 & 12.67 & 12.33 & 12 \\
\hline Ow9106 & 43 & 45.67 & 38 & 48.67 & 48 & 30 \\
\hline Ow9107 & 38 & 52 & 35 & 32.33 & 42.33 & 29 \\
\hline Ow9109 & 12 & 10.67 & 9.67 & 12 & 10.67 & 11.33 \\
\hline Ow9111 & 6 & 2.67 & 0.33 & 16.33 & 2 & 10.33 \\
\hline Ow9113 & 15.67 & 14.33 & 13.33 & 15.67 & 18.33 & 13.33 \\
\hline Ow9115 & 6.67 & 0.33 & 0.33 & 6.67 & 6 & 1.33 \\
\hline Ow9116 & 12 & 12.67 & 12 & 12 & 12.67 & 11.33 \\
\hline Ow9117 & 13.33 & 14 & 15 & 15 & 16 & 14.33 \\
\hline Ow9119 & 0 & 0 & 0 & 0 & 0 & 0 \\
\hline Ow9120 & 8 & 10 & 9.33 & 8 & 10 & 7 \\
\hline Ow9121 & 4.67 & 5.33 & 5.67 & 11.67 & 10.33 & 9.67 \\
\hline
\end{tabular}




\begin{tabular}{|c|c|c|c|c|c|c|}
\hline Ow9122 & 9 & 9.67 & 10.67 & 9 & 9.67 & 7.33 \\
\hline Ow9123 & 11.67 & 7.67 & 7.67 & 10 & 9 & 9 \\
\hline Ow9124 & 5 & 10 & 9.67 & 12.67 & 12.67 & 12.67 \\
\hline Ow9125 & 7.67 & 9 & 7 & 11.33 & 11.67 & 9.33 \\
\hline Ow9126 & 9.67 & 15 & 10 & 24 & 20.33 & 12.33 \\
\hline Ow9127 & 13.33 & 11.67 & 8.67 & 13.33 & 11.33 & 11 \\
\hline Ow9128 & 0 & 1.33 & 0 & 0 & 1.33 & 1.33 \\
\hline Ow9129 & 5 & 10.67 & 11.33 & 12 & 11 & 11.33 \\
\hline Ow9132 & 0 & 0 & 0 & 0 & 0 & 0 \\
\hline Ow9133 & 0.67 & 1.67 & 0 & 0.67 & 1.67 & 0 \\
\hline Ow9134 & 18 & 13.67 & 16.67 & 18 & 13.67 & 18.67 \\
\hline Ow9137 & 5 & 7.67 & 3.67 & 8.33 & 11 & 8 \\
\hline Ow9138 & 10.67 & 10 & 8 & 15 & 15.67 & 12.33 \\
\hline Ow9139 & 18.67 & 20 & 20 & 17.33 & 17.33 & 15 \\
\hline Ow9140 & 6.67 & 9 & 9 & 6.67 & 11.67 & 10.67 \\
\hline Ow9142 & 10.67 & 10.33 & 9.67 & 10.67 & 10.67 & 12.67 \\
\hline Ow9143 & 16.67 & 12 & 9.33 & 13 & 12.33 & 9.33 \\
\hline Ow9144 & 21.33 & 15 & 16 & 16 & 14.33 & 14.67 \\
\hline Ow9147 & 16.33 & 18 & 13.67 & 16.33 & 18 & 11.33 \\
\hline Ow9148 & NA & 16 & $16 \mathrm{NA}$ & & 16 & 8 \\
\hline Ow9149 & 0 & 0 & 0 & 0 & 0 & 0 \\
\hline Ow9150 & 0 & 0 & 0 & 0 & 0 & 0 \\
\hline Ow9151 & NA & 12.33 & $12 \mathrm{NA}$ & & 12.33 & 13.33 \\
\hline Ow9152 & 13.33 & 13.33 & 16.33 & 13.33 & 15 & 20 \\
\hline Ow9153 & 0 & 2.33 & 2.33 & 3.67 & 2.33 & 3 \\
\hline Ow9154 & 16.33 & 15.33 & 15.33 & 16.33 & 15 & 12.33 \\
\hline Ow9155 & 8 & 9 & 9 & 11.67 & 11.67 & 10.33 \\
\hline Ow9156 & 8.33 & 8 & 7.67 & 11.67 & 11.67 & 10.67 \\
\hline Ow9158 & NA & 9 & $3 \mathrm{NA}$ & & 8.67 & 4 \\
\hline Ow9159 & 9.67 & 10 & 10.67 & 11 & 12.33 & 11.33 \\
\hline Ow9160 & 17 & 15.33 & 10 & 12 & 12.33 & 14.33 \\
\hline Ow9161 & 10.33 & 9.67 & 10 & 10.33 & 12 & 7.33 \\
\hline Ow9163 & 0.67 & 2.33 & 0 & 0.67 & 2.33 & 0.67 \\
\hline Ow9166 & 0 & 0 & 0 & 2 & 0 & 0 \\
\hline Ow9167 & 11 & 9.67 & 10 & 11 & 9.67 & 10 \\
\hline Ow9168 & 6.33 & 9 & 7 & 6.33 & 9 & 6 \\
\hline Ow9169 & 10.67 & 10.67 & 11 & 10.67 & 10.67 & 11.33 \\
\hline Ow9171 & 0 & 0.67 & 0 & 0 & 0.67 & 0 \\
\hline Ow9172 & 13.33 & 16.33 & 17 & 13.33 & 16.33 & 15.33 \\
\hline Ow9173 & NA & 16.67 & 16.67 NA & & 16.67 & 16.67 \\
\hline Ow9174 & NA & 8 & 8 & 13.33 & 8 & 5.33 \\
\hline Ow9175 & 11.67 & 9 & 8.33 & 13.33 & 14 & 12.33 \\
\hline Ow9178 & 0 & 0 & 0 & 0 & 0 & 0 \\
\hline Ow9179 & 12.67 & 13 & 12.33 & 12.67 & 12.67 & 16.33 \\
\hline Ow9180 & 11 & 10.33 & 10.67 & 11 & 11.33 & 12.33 \\
\hline Ow9181 & 0 & 0 & 0 & 0 & 0 & 0 \\
\hline Ow9182 & $7.67 \mathrm{NA}$ & & 7.67 & $9.67 \mathrm{NA}$ & & 3.67 \\
\hline Ow9185 & 12.67 & 11.33 & 11.67 & 12.67 & 11.33 & 11.67 \\
\hline Ow9186 & $0 \mathrm{NA}$ & & 2.67 & 4.67 NA & & 2 \\
\hline Ow9190 & 11.67 & 16.33 & 10.67 & 11.67 & 13 & 13 \\
\hline Ow9191 & 2.67 & 7.33 & 7.67 & 9.67 & 9 & 8.67 \\
\hline
\end{tabular}


11.33 